\title{
Corso, comercio y navegación en el siglo Xv: Castilla y las galeras mercantiles de Florencia $^{1}$
}

\author{
Corsarism, Commerce and Navigation in the XVth Century: \\ Castile and the Mercantile Galleys of Florence
}

\author{
Raúl GonZÁlez ArÉvalo \\ Universidad de Sevilla \\ ragonare@yahoo.es
}

\begin{abstract}
RESUMEN
Florencia desarrolló un sistema estatal de galeras en el siglo xv. El presente artículo analiza su papel en la Corona de Castilla, tanto en las órdenes del Consulado del Mar como en la documentación privada. Así, se estudian aspectos tan dispares como la inserción de los puertos castellanos en las líneas de navegación florentinas, los incidentes corsarios, los fletes previstos y las noticias sobre la práctica mercantil. Emerge una imagen inédita sobre el papel de las galeras toscanas en la articulación comercial exterior de la Corona de Castilla.
\end{abstract}

Palabras clave: Galeras. Florencia. Castilla. Cádiz. Sanlúcar de Barrameda. Comercio. Corso. Historia de la navegación

\begin{abstract}
Florence developed a system of state galleys in the 15th century. The present article analyzes its role in the Crown of Castile, through the Sea Consul's orders as well as in private documentation. It studies aspects as diverse as the insertion of Castilian ports into Florentine navigational lines, corsair incidents, freight charges envisaged and news about mercantile practices. There emerges a previously unknown image of the role of Tuscan galleys in the external commercial organization of the Crown of Castile.
\end{abstract}

Keywords: Galleys. Florence. Castile. Cadiz. Sanlucar de Barrameda. Commerce. Corsairs. Navigation History.

SUMARIO: 1. Florentinos en la Baja Andalucía. 2. Castilla en la ruta de Poniente. 3. Las galeras de Berbería.

4. Cádiz en los fletes de las galeras mercantiles de Florencia. 5. Florentinos y genoveses: el comercio de las galeras. 6. Cádiz en los seguros marítimos de la ruta de Poniente. 7. Algunas consideraciones finales. 8. Apéndice documental.

${ }^{1}$ El presente artículo forma parte del proyecto "Andalucía, el Reino de Granada y Florencia en el siglo XV", financiado por el programa de Becas Postdoctorales del Ministerio de Educación, desarrollado en la Universidad de Florencia en 2005-2007. Abreviaturas empleadas: Archivio di Stato di Firenze (ASF); Consoli del Mare (CM); Notarile Antecosimiano (NA); Mediceo avanti il Principato (MAP). 


\section{FLORENTINOS EN LA BAJA ANDALUCÍA}

El estudio de las naciones italianas en suelo ibérico, y más concretamente en el suroeste peninsular, ha privilegiado tradicionalmente la presencia genovesa. Las razones son múltiples, siempre en torno al comercio: desde los tratados firmados con la Superba hasta el tráfico de mercancías, pasando por la presencia y el desarrollo de colonias en los principales centros comerciales del litoral. Es un hecho fácilmente comprobable con un vistazo somero a la bibliografía disponible ${ }^{2}$.

De la misma manera, la mayor visibilidad de los venecianos a través de su conocido sistema de mude, cuyas galeras conectaban a la Serenissima con los mercados de todo el Mediterráneo y el Mar del Norte, ha llamado oportunamente la atención sobre su presencia en el sur de la Península Ibérica³.

Por el contrario, la presencia de los toscanos, y más concretamente de la nación florentina, ha pasado más desapercibida. En el Reino de Sevilla su conocimiento

\footnotetext{
${ }^{2}$ Sin pretender en absoluto ser exhaustivos, cf. Boscolo, Alberto: "Genova e Spagna nei secoli XIV e XV: una nota sugli insediamenti”, en Atti I Convegno internazionale di Studi Colombiani, Génova, 1974, s.p.; isdem, "Gli insediamenti genovesi nel sud della Spagna all'epoca di Cristoforo Colombo", en Atti II Convegno internazionale di Studi Colombiani, Génova, 1977, pp. 319-44; HeErs, Jacques: "Les hommes d'affaires italiens en Espagne au Moyen Age: le marché monetaire", en Societé et économie à Gênes (XIV -XV $V^{e}$ siècles), Londres, 1979, VIII, pp. 74-83; idem, "Los genoveses en la sociedad andaluza del siglo Xv: orígenes, grupos, solidaridades", en Hacienda y comercio. Actas del II Coloquio de Historia Medieval Andaluza, Sevilla, 1982, pp. 419-444; LAdERo QuesadA, Miguel Ángel: "Los genoveses en Sevilla y su región (siglos XIII-XVI): elementos de permanencia y arraigo", en Los Mudéjares de Castilla y otros estudios de historia medieval andaluza , Granada, 1989, pp. 283-312; D'Arienzo, Luisa: "Le colonie genovesi di Siviglia, Cadice, Jerez de la Frontera e Puerto de Santa María alla vigilia del viaggio di scoperta colombiano attraverso una fonte fiscale sulla guerra di Granada (l'assedio di Baza del 1489)" en D'Arienzo, Luisa (ed.): Sardegna, Mediterraneo e Atlantico tra Medioevo e Età Moderna III, Roma, 1993, pp. 133-83; Bello León, Juan Manuel: Extranjeros en Castilla (1474-1501). Notas y documentos para el estudio de su pr esencia en el reino a fnes del siglo XV, La Laguna, 1994; IguAL LuIs, David y Navarro Espinach, Germán: "Los genoveses en España en el tránsito del siglo Xv al Xvi”, Historia. Instituciones. Documentos, 24 (1997), pp. 261-332; Fossati RaItieri, Silvana: "Presenze genovesi a Siviglia nella seconda metà del Quattrocento", Anuario de Estudios Medievales, 24 (1994), pp. 299-312; eadem, "La nazione genovese tra Cordova e Siviglia nel secondo '400", en PetTi Balbi, Giovanna (ed.): Comunità forestiere e "nationes” nell'Europa dei secoli XIII-XVI, Nápoles, 2001, pp. 283-297.

${ }^{3}$ Cf. López de Coca Castañer, José Enrique: "La "muda" de Berbería en las fuentes españolas", en Trillo San José, Carmen (ed.): Relaciones entre el Mediterráneo cristiano y el Norte de África en época medieval y moderna, Granada, 2004, pp. 361-401; isdem, "Las galeras venecianas de Poniente y Berbería desde la perspectiva española”, Medievalismo, 16 (2006), pp. 113-72.
} 
está básicamente ligado a las empresas colombinas ${ }^{4}$. Tampoco los autores italianos parecen haber prestado mucha atención al tema, con algunas excepciones ${ }^{5}$.

No cabe duda de que la dispersión y la fragmentación de las fuentes complican sobremanera su estudio en un área que, evidentemente, no fue primordial en los intereses políticos y comerciales toscanos. Con todo, una investigación más detenida en algunas de las fuentes disponibles, florentinas en su inmensa mayoría, ha permitido ir sacando a la luz recientemente el conocimiento que en la Signoria de Florencia se tenía sobre el litoral andaluz atlántico, los contactos comerciales en las rutas de distribución entre el Mediterráneo y el Atlántico, y unas relaciones diplomáticas que permanecían inéditas hasta ahora ${ }^{6}$.

La profundización en las relaciones comerciales entre Florencia y Castilla, más allá de la información contenida en los libros de mercaderías, que presentan una problemática específica que ya hemos tenido ocasión de abordar con anterioridad, encuentra dos escollos insalvables: de una parte, el examen de los libros contables, memoriales y ricordanze de las compañías florentinas conservados en el Archivio di Stato di Firenze se ha revelado infructuoso para el período estudiado; efectivamente, apenas hay noticias sueltas en la actividad mercantil de los Cambi y de los Martelli, como veremos más adelante. De otra, a diferencia de genoveses y venecianos, que firmaron tratados comerciales y obtuvieron privilegios en Castilla ${ }^{7}$, los florentinos

${ }^{4}$ Cf. Boscolo, Alberto: "Fiorentini in Andalusia all'epoca de Cristoforo Colombo", en Studi di Storia economia toscana nel Medioevo e nel Rinascimento in memoria de Federigo MelisRoma, 1987, pp. 78-85; isdem, "Fiorentini in Andalusia all'epoca di Cristoforo Colombo", en Presencia italiana en Andalucía, Siglos XIV-XVII, Sevilla, 1989, pp. 1-10; VARELA, Consuelo: "El entorno florentino de Cristóbal Colón", en Boscolo, Alberto y Torres, B. (coords.): La presenza italiana in Andalusia nel basso medioevo, Roma, 1985, pp. 125-134; eadem, Colón y los forentinos, Madrid, 1988; eadem, "Vida cotidiana de los florentinos en la Sevilla del Descubrimiento", en Presencia italiana ..., pp. 11-22.

${ }^{5}$ Efectivamente, comparada con la bibliografía sobre toscanos en Inglaterra, los Países Bajos, Portugal y el Magreb, los estudios específicos de investigadores italianos sobre la presencia de toscanos en la Andalucía cristiana son muy escasos: el ya citado Alberto Boscolo y, de manera dispersa en muchos trabajos, Federigo Melis. El reducido espacio que ocupa el sur peninsular en la expansión global de los toscanos por el Mediterráneo es fácilmente comprobable recurriendo a una visión de conjunto: BALLETTO, Laura: “I Toscani nel Mediterraneo: L'Occidente, L'Africa, Cipro”, en GensinI, Sergio (ed.): La Toscana nel secolo XIV. Caratteri di una civiltà regionale, Pisa, 1988, pp. 251-269.

${ }^{6}$ Se trata de diferentes trabajos procedentes del proyecto postdoctoral en el que se enmarca el presente estudio. Sobre la costa meriodional ibérica cf. GonZÁlez Arévalo, Raúl: "La costa del Reino de Sevilla en la documentación náutica italiana (siglo xv)", en Malpica Cuello, Antonio, Peinado Santaella, Rafael G. y Fábregas García, Adela, Historia de Andalucía. VII Coloquio, Granada, 2010, CD-ROM, pp. 301-317. Sobre los contactos diplomáticos cf. "La guerra di Granada nelle fonti fiorentine", Archivio Storico Italiano, 609 (2006), pp. 387-418; "Note sui rapporti diplomatici tra la Castiglia e Firenze nell'inizio del Quattrocento", Archivio Storico Italiano, 617 (2008), pp. 533-548. Para las noticias comerciales cf. "Las cartas de Francisco Bernal: un factor castellano en el Archivio Datini", Baetica, 28 (2006), pp. 337-349; "La moneda castellana en los manuales de mercaderías y tratados de aritmética italianos bajomedievales (siglos XIII-XV)", Baetica, 29 (2007), pp. 263-280; "Comercio exterior del Reino de Sevilla a través de los manuales de mercaderías italianos bajomedievales", en prensa.

7 González Gallego, Ignacio: "El Libro de los privilegios de la nación genovesa", Historia. Instituciones. Documentos, 1 (1974), pp. 275-358. López de Coca CASTAÑer, José Enrique: "Las galeras venecianas...", pp. 133-34. 
no sellaron las relaciones comerciales a través de ningún texto oficial. Al menos, no se han hallado trazas en este sentido en las secciones consultadas hasta ahora entre los fondos de su inmenso Archivio di Stato. Más aún, cuando en 1405 Enrique III de Castilla ofreció una alianza a la República de San Juan contra el Reino de Granada a cambio de ayuda para conseguir que Génova le vendiera Pisa, la Señoría florentina la rechazó, alegando algunos miembros del Consejo, entre otras razones, que "liga non fiat cum eo pro salute mercatorum": la república entendía que las alianzas políticas podían perjudicar las actividades de sus mercaderes.

De hecho, un análisis de la política comercial desarrollada en el exterior hasta entonces muestra que, lejos de existir una actuación unitaria como natio, la tendencia preferente era que cada compañía operara por su cuenta, incluso asimilándose sus miembros como componentes de otra nación, posibilidad recogida en los estatutos de las colonias florentinas en el extranjero'. Es una práctica que el cronista Giovanni Villani ya refería en la primera mitad del siglo XIV sobre los florentinos en Túnez: "i Fiorentini si spacciavano in Tunisi per Pisani" ${ }^{10}$. Así, los operadores florentinos podían actuar de manera encubierta, incluso beneficiándose de las prerrogativas otorgadas a otras naciones. Una muestra significativa sobre esta forma de operar la ofrece Francesco Balducci Pegolotti que, en su famoso manual de mercadería, contemporáneo de la Nuova Cronica de Villani, al referirse al almojarifazgo sevillano (señalado en un $10 \%$ del valor de las mercancías) recogía asimismo las excepciones: "Gienovesi e catalani e piagentini e la compagnia de' Bardi pagano pure 5 a centinaio, e così chiunque va brivilegiato di franchigia dal signore", revelando de esta manera que, entre los florentinos, sólo la compañía de los Bardi disfrutaba del mismo privilegio concedido a genoveses, catalanes y placentinos ${ }^{11}$.

En cualquier caso, conquistada Pisa en 1406 y tras la adquisición de Porto Pisano y Livorno en 1421 Florencia decidió convertirse en una potencia naval, siguiendo el modelo veneciano, desarrollando entre 1422 y 1480 un sistema de galeras que asegurara los contactos comerciales con todo el Mediterráneo y el Mar del Norte, con el respaldo y la seguridad que debía proporcionar la república. Las cuatro líneas principales puestas en servicio respondían a las cuatro áreas estratégicas para la economía florentina de la primera mitad del siglo xv: Catalogna (la Corona de Aragón y Sicilia); Ponente (Inglaterra y los Países Bajos); Barberia (el Magreb central) y Levante (Egipto-Siria).

Sin el marco de un tratado comercial ni documentación relevante sobre las actividades de las compañías florentinas en el Reino de Sevilla, el estudio de la actuación de las galeras mercantiles florentinas en los puertos atlánticos castellanos se demuestra más importante aún para profundizar en la articulación de la presencia toscana y su papel en la proyección comercial exterior en un período, además, en el

${ }^{8}$ Cf. GonzÁlez Arévalo, Raúl: "Note sui rapporti...”, p. 540.

${ }^{9}$ MASI, Gino: Statuti delle colonie forentine all'estero (sec. XV-XVI), Milán, 1941, p. XIII.

${ }^{10}$ VILlani, Giovanni: Nuova Cronica (edizione critica a cura di Giuseppe Porta), vol. I, Parma, 1990, Libro I, Capitolo LIII.

${ }^{11}$ Cf. Evans, Allan (ed.): Francesco Balducci Pegolotti. La pratica della mer catura, Cambridge (Massachusetts), 1936, p. 270. 
que la escasez de fuentes autóctonas constituye un serio obstáculo para ahondar en estos aspectos.

\section{CASTILLA EN LA RUTA DE PONIENTE}

El estudio de las galeras estatales de Florencia tiene una referencia única de obligado conocimiento para quien se acerca al tema, siendo el punto de partida para toda investigación que aspire a profundizar en él: la monografía de Michael E. Mallett ${ }^{12}$. A él nos remitimos para el conocimiento general del sistema en el contexto económico florentino. Nos interesa más recordar las dificultades encontradas para ahondar en la cuestión: la ausencia de registros oficiales continuos sobre el comercio florentino y el movimiento de naves. Efectivamente, no se han conservado los libros portuarios de Livorno ni de Porto Pisano, y los registros de los Cónsules del Mar son incompletos y discontinuos, apenas contienen detalles relevantes referentes a los viajes de las galeras y sus cargamentos durante la década de 1460 . De hecho, su publicación previa no había encontrado continuidad en la historiografía específica ${ }^{13}$.

Por otra parte, como todas las disposiciones oficiales, muestran la organización ideal del sistema estatal, la teoría, pero no revelan demasiados particulares sobre su funcionamiento real. De hecho, para conocer con mayor detenimiento la navegación de las galeras Mallett tuvo que complementar la documentación conservada en los archivos florentinos con registros procedentes del Public Record Office de Londres, el Archivo de la Corona de Aragón y el Archivo del Reino de Valencia ${ }^{14}$; preciosa se revela además la información del diario de Luca di Maso degli Albizzi, capitán de las galeras de Poniente en 1429-1430, publicado como apéndice ${ }^{15}$. Con todo, el propio autor reconoce que demasiadas preguntas quedan en el aire.

Michael Mallett ha demostrado que las regulaciones de calendario no se pueden tomar como evidencias de que la navegación se llevara efectivamente a cabo, de forma que hay que recurrir a documentación suplementaria para conocer con seguridad el funcionamiento de las líneas ${ }^{16}$. Además, en nuestro caso, no figurando las costas de Castilla entre las áreas económicas preferentes de Florencia, la información sobre la actuación de las galeras mercantiles en su litoral pasa por el estudio de las dos rutas que las incluían en su recorrido: las galeras de Poniente y Berbería.

La actividad de las galeras de Poniente es la mejor documentada del sistema estatal florentino y, en algunos sentidos, era la más importante para la economía de

12 Mallett, Michael E.: The Florentine Galleys in the Fifteenth Century, Oxford, 1967.

13 Efectivamente, el profesor Grunzweig publicó los fondos del Consulado del Mar en francés, a veces de manera íntegra, otras ofreciendo regestos, según la importancia otorgada a los documentos. Cf. Grunzweig, Armand: "Les fonds du Consulat de la Mer aux archives de l'État de Florence", Bulletin de l'Institut historique belge de Rome, 10 (1930).

${ }^{14}$ Los archivos valencianos han proporcionado información adicional sobre las galeras florentinas en investigaciones más recientes. Cf. IguAL LuIs, David: Valencia e Italia en el siglo XV: rutas, mercados y hombres de negocios en el espacio económico del Mediterráneo occidental, Castellón, 1998.

15 Mallett, Michael E.: The Florentine Galleys..., pp. 193-280.

16 Ibidem..., pp. 62-63. 
la República del Arno dado que su objetivo principal era garantizar el suministro de lana inglesa, vital para la industria lanera florentina ${ }^{17}$.

El viaje de inauguración de la nueva ruta tuvo lugar en 1425, aunque el segundo no se repitió hasta 1427. Parece bastante claro que los viajes de 1428 y 1429 coincidieron con otras iniciativas enteramente privadas, como el de la galera de Priore di Marioto, que en otoño de 1429 hacía escala en Aigües Mortes, La Nouvelle, Collioure, Barcelona, Valencia, Málaga, Cádiz y Lisboa antes de dirigirse hacia el Mar del Norte ${ }^{18}$. Sin embargo, se trata de una circunstancia que no parece haberse dado muy a menudo en los años siguientes.

En 1429 se decidió que en vez de enviar un convoy de tres galeras una vez al año zarparían dos flotas de dos galeras en febrero y en septiembre ${ }^{19}$. Pero, no hay nuevas evidencias de que las galeras florentinas levaran anclas en dirección a Flandes e Inglaterra hasta 1436: la guerra con Luca primero y la crisis política interna debido a la expulsión y nueva restauración de los Medici después probablemente fueron determinantes.

El viaje de 1439 retrasó su partida hasta diciembre. Lo tardío de la fecha y la necesidad urgente de lana determinaron que la flota navegara directamente hasta Inglaterra, con órdenes expresas de detenerse sólo en Mallorca y Cádiz. Sin embargo, desde entonces y hasta el estallido de la guerra con Alfonso de Aragón (1447) dos galeras zarparon regularmente cada otoño con destino al Mar del Norte.

Un examen detenido de los viajes hasta el comienzo del conflicto con la Corona de Aragón muestra que en las escalas previstas en la ruta se operaron distintas modificaciones sucesivas. Así, el diario de Luca di Maso degli Albizzi revela que en el viaje de 1429-1430 las galeras de Poniente se detuvieron en Porto Pisano, Marsella, Port-de-Bouc, Aigües Mortes, Barcelona, Valencia, Mallorca, Denia, Jávea, Benidorm, Villajoyosa, Alicante, Almería, Málaga, Cádiz, Lisboa, Pontevedra, Ribadeo, Southampton y Sluys a la ida, mientras que a la vuelta siguieron la ruta Sluys-Lisboa-Cádiz-Málaga-Almería-Jávea-Mallorca-Gorgona-Porto Pisano ${ }^{20}$.

El 22 de enero de 1443 los Cónsules del Mar notificaban el siguiente recorrido en el capítulo del capitán de las galeras de Poniente: Porto Pisano-Aigües MortesBarcelona-Valencia-Málaga-Cádiz-Flandes-Southampton a la ida, mientras que el tornaviaje seguiría la ruta Southampton-Cádiz-Málaga-Valencia-Barcelona-San Felíu de Guixols-Aigües Mortes-Porto Pisano. Con todo, el capitán, de acuerdo con los patrones, podría detenerse en otros puertos de la misma ruta si lo juzgara conveniente, mientras que para la vuelta, si las galeras tenían suficiente carga, estarían autorizadas a realizar una única escala técnica sólo en $\mathrm{Cádi}^{21}$. Algunas variaciones más encontramos en las instrucciones para las galeras de Poniente en 144722:

\footnotetext{
${ }^{17}$ Para una descripción más completa de las galeras de Poniente ver ibidem, pp. 82-98.

${ }^{18}$ Ibidem, p. 84.

${ }^{19}$ ASF, CM, III, fol. 26 y v v; Grunzweig, Armand: “Les Fonds...", pp. 11-13.

${ }^{20}$ El diario en Mallett, Michael E.: The Florentine Galleys..., pp. 207-275.

${ }^{21}$ ASF, CM, V, 5, 21-I-1443. Cf. Asismimo GrunzweIG, Armand: "Les Fonds...”, p. 53.

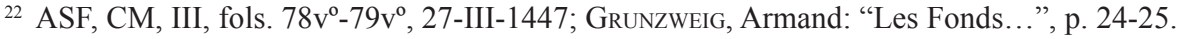


Fiandria: allo andare può fare queste schale et non altre: parte di Porto Pisano, Bocholi, Sanfilio, Maiolicha, Valença, Sciabbia, Villagoiosa, Denia, Cantera, Almeria, Malicha, Chadis, Lisbona, Colonne, Schiuse, Sanduicci, Antona. Et di ritorno possi fare le medesime schale ciò è da Antona in Chadis, Malicha, Porto Pisano. Non si può fare altre schale che le sopradette così nello andare come nel tornare.

Puede observarse que los puertos del norte peninsular, Pontevedra y Ribadeo, tras la visita del convoy capitaneado por Albizzi en 1429, no comparecen nunca en las órdenes oficiales, quizás por los problemas de piratería a los que se enfrentó, como veremos más adelante. Por su parte, la escala de Lisboa se manifiesta de manera intermitente: la visitó Albizzi en 1429, no estaba prevista en las órdenes de 1443, para volver de nuevo en las de 1447.

Según Mallett las guerras con Alfonso V el Magnánimo determinaron de manera drástica que las galeras prácticamente no zarparan entre 1448 y $1455^{23}$, aunque habría habido serios intentos de que la empresa continuara en 1448,1451 y 1453 . No hay más noticias hasta el viaje de 1460-1461, cuando se sabe por una carta de Angelo Spini, patrón de las galeras de Berbería de ese año, que las galeras de Poniente llegaron a Cádiz en el tornaviaje el 2 de julio de 1461, y cinco días más tarde retrocedieron hasta Sanlúcar de Barrameda (el rio di Sibilia), donde permanecieron tres más, entre el 7 y el 10 de julio, antes de retomar el camino de vuelta. Es una circunstancia especialmente llamativa por cuanto que Sanlúcar no aparece nunca prevista en las órdenes de Poniente, pues era una escala reservada a las galeras de Berbería, cuyos patrones protestaron formalmente a los de Poniente por el evidente perjuicio que se derivaba para el comercio de la coincidencia de dos líneas en un mismo puerto (ànovi ghuasto questo partito, e a noi chosta questo viaggio) ${ }^{24}$.

Para el viaje de Flandes e Inglaterra que debía partir en otoño de 1461 se conservan de nuevo las instrucciones para el capitán de las galeras, con capítulos prácticamente idénticos a los de 1443, estableciendo escalas similares, aunque algunas a elegir por los patrones: Porto Pisano-Savona-Marsella/Port de Bouc-Aigües MortesSan Felíu de Guixols/Barcelona-Valencia-Denia-Jávea-Alicante-Almería-MálagaCádiz-Sluys-Southampton, mientras que a la vuelta podían tocar tierra en Cádiz, Málaga y Jávea ${ }^{25}$. No contamos con más datos oficiales sobre las escalas previstas para las galeras de Poniente en los años sucesivos hasta la desaparición del sistema

${ }^{23}$ Elisa Soldani, al estudiar la primera fase del conflicto entre el monarca aragonés y Florencia, ha revelado que las galeras estatales desarrollaron funciones militares durante la contienda. Cf. SoLDANI, Maria Elisa: "Alfonso il Magnanimo in Italia: pacificatore o crudel tiranno? Dinamiche politico-economiche e organizzazione del consenso nella prima fase della guerra con Firenze (1447-1448)", Archivio Storico Italiano, CLXV (2007), pp. 266-324.

24 "Le nostre ghalee di Ponente arivorono in Chadisi sino a dì 2 di lulglio, dipoi a dì 7 se ne venono qui nel rio deto". ASF, MAP, X, 211, 18-VII-1461. Ver Apéndice. Las galeras venecianas hacían la misma distinción, preservando Sanlúcar para la línea de Berbería, mientras que las de Poniente recalaban en Cádiz. Cf. López de Coca Castañer, José Enrique: "La “muda" de Berbería...”, p. 367.

${ }^{25}$ ASF, CM, IV, 6, fol. 25. Es una información que se repite en ASF, CM, III, fol. 132 $\mathrm{v}^{\mathrm{o}}$, recogida asimismo en francés en Grunzweig, Armand: "Les Fonds...", p. 32. 
tras el último viaje en 1477-1478, pero cabe suponer que, grosso modo, seguirían las directrices esbozadas hasta el momento.

En todo caso, para el tema que nos ocupa, hay que destacar que Cádiz está siempre presente, hecho que cabe subrayar para el viaje de regreso hacia Porto Pisano cuando, con las galeras completamente cargadas de lana inglesa, la tendencia era eliminar etapas para acelerar la llegada. Otro indicador de la importancia de las escalas lo constituyen los días estipulados para cada una de ellas, de lo que se deduce que la parada más importante en el meridión ibérico era el puerto gaditano. Desafortunadamente, las instrucciones de 1447 no reflejan la duración prevista en cada puerto, lo que limita este análisis a las órdenes de 1443 y 1461, cuando para Cádiz se previeron dos y seis días respectivamente, frente a una y tres jornadas en Málaga, la otra escala que articulaba la ruta del Estrecho.

No parece probable que las sucesivas modificaciones de la ruta afectaran a la posición otorgada: en las órdenes de enero de 1461 el Consiglio dei Cento deja a elección de conductores y patrones la decisión de ir a Flandes e Inglaterra bien siguiendo la vía de Provenza, como hasta entonces, bien surcando la ruta Porto Pisano-Palermo-Mallorca-Valencia, para continuar después como estaba previsto (Denia-JáveaAlicante-Almería-Málaga-Cádiz-Sluys-Southampton) ${ }^{26}$. De igual modo, la decisión de agosto de 1463 de iniciar el viaje de Poniente acudiendo a Civitavecchia a cargar alumbre antes de continuar hacia Norte no afectaría a las visitas ibéricas por debajo de Valencia ${ }^{27}$. Además, se sabe que en febrero de 1468 las dos galeras de Poniente se detuvieron en Cádiz en el tornaviaje ${ }^{28}$.

Naturalmente, las instrucciones oficiales y las escalas previstas en las distintas rutas no deben esconder la realidad de una navegación de cabotaje, hecho ya apuntado para los itinerarios de las mude venecianas ${ }^{29}$. En este sentido, cabe recordar que la documentación náutica italiana - portulanos y cartas náuticas- revela un conocimiento detallado de las costas atlánticas andaluzas ${ }^{30}$.

Además, cabe tener en cuenta los imprevistos, que podían modificar las instrucciones originales; en el caso concreto de las galeras florentinas el diario del capitán Luca di Maso degli Albizzi muestra claramente estos dos puntos, la navegación de cabotaje y las circunstancias inesperadas una vez superado el Estrecho de Gibraltar. Así, las malas condiciones del mar y el viento contrario obstaculizaron el paso del Estrecho: el 20 de octubre de 1429, en su viaje hacia el norte, Albizzi anotó que tuvieron que parar en Tarifa

perché s'era messo vento a ponente et per levare rinfreschamento; [...] alla mezza nocte partimo di detto luogho [...] et pocho fuori del porto trovamo il vento in prua, per che surgemo forse uno miglio da ponente a Tariffi, et così stemo tutta nocte.

${ }^{26}$ ASF, CM, III, fol. 138, 23-I-1461.

${ }^{27}$ Ibidem, fols. $162 \mathrm{v}^{\circ}-163,31-$ VIII-1463.

${ }^{28}$ Cf. Mallett, Michael E.: “Anglo-Florentine Commercial Relations, 1465-1491”, The Economic History Review, Second Series, Volume XV-2 (December 1962), p. 255.

${ }^{29}$ Hocquet, Jean-Claude: "Itinerarios del comercio marítimo (siglos XV-XVI)", en idem, Comercio marítimo en el Mediterráneo medieval y moderno, Granada, 2002, p. 151.

${ }^{30}$ Cf. González Arévalo, Raúl: "La costa del Reino de Sevilla...", passim. 
Al día siguiente, 21 de octubre, "ci partimo da detto luogho con vento scarso e navichamo tutto dì voltegiando; la sera surgemo tra Tariffi e Traficata, forse miglia X larghi da Tariffi, et così stemo tutta la nocte"; las condiciones desfavorables les hicieron retroceder el 22 de octubre hasta Algeciras (Zizara):

Sabato mattina al'alba del dì, essendo rinforzato il mare e 'l vento nostro contrario, parendoci non stare bene in detto luogho tornamo indietro a Tariffi et quivi surgemo con asai di tempo; et circha ora di nona, crescendo il mare e 'l vento rinfreschava et ne' luogho faceva fortuna assai perch'era paragho, ci levamo con assai faticha et pericolo non potendo girare la galea per essere troppo caricha et scademo assai, convenne pigliare volta contraria. Aiutocci l'essere stati larghi et tornamo indietro alla Zizara presso al monte Giubeltaro.

Los contratiempos, sin embargo, no acabaron ahí:

Domenicha adì 23, passata terza, ci partimo dalla Zizera per andare a nostro viaggio. Come fumo al capo, trovamo vento et mare contrario, e però surgemo a capo di Canpo et quivi pigliamo aqua et legno [per] le galee. La mattina fe' fare la mostra alla galea conserva.

Con muchas dificultades consiguieron entrar en el puerto de Cádiz al día siguiente, 24 de octubre:

Lunedì adì 24 d'octobre innanzi dì 2 ore o circha, ci partimo da Canpo con vento a sciloccho, et surgemo circha a ora di vespro a Cadisi in Spagna; et giunti alla boccha del porto, manchò il vento et missesi vento a libeccio nostro contradio, ma fu utile a entrare nel porto.

En consecuencia, el estado de la mar en otoño obligó al convoy a detenerse en Tarifa y Algeciras, escalas no previstas en las órdenes oficiales. El regreso se realizó sin incidentes ${ }^{31}$. Por el contrario, el retroceso de las galeras de Poniente en julio de 1461 desde Cádiz hasta Sanlúcar, en pleno verano, no se puede explicar debido a dificultades en la navegación y cabe atribuirlo más bien a cuestiones de seguridad o a intereses comerciales, aunque no hay nada claro en este sentido.

El diario de Albizzi revela además otra práctica que debió ser habitual: el reclutamiento de marineros castellanos para la travesía del Atlántico, debido fundamentalmente a las condiciones de la navegación oceánica, tan diferentes de las del más tranquilo Mediterráneo. Efectivamente, en Cádiz los florentinos reclutaron a tres marinos: Iohanni Martini, Iohanni Gratia di Chitana y Ihoanni Gratia da Villa Bitrosa (Juan Martínez y Juan García, vascos de Guetaria, y Juan García, de Villaviciosa) ${ }^{32}$.

${ }^{31}$ Para el relato del paso por las costas andaluzas, a la ida como a la vuelta del viaje a Flandes e Inglaterra de 1429-30, cf. Mallett, Michael E.: The Florentine Galleys..., pp. 222-224 y 268-269.

${ }^{32}$ Mallett considera que la aportación de los marinos castellanos era fundamental no sólo por las condiciones de la navegación atlántica, sino también debido al desconocimiento que tenían los toscanos de las costas andaluzas, hecho que negaría la documentación náutica italiana conservada en los archi- 
Otro ejemplo más lo proporciona el registro de los gastos de las galeras de Poniente que llegaron a Porto Pisano el 7 de mayo de 1467. Efectivamente, entre los desembolsos figuran 350 florines "per la metà de' piloti di Spagna", sin que se precise nada más. Más explícito es el registro que revela que por "uno piloto levato in Chadis per la Barberia sino Porto Pisano fiorini 30 larghi”" ${ }^{33}$.

Este último registro resulta un tanto confuso al plantear nuevos interrogantes sobre la ruta de vuelta: hemos visto en las instrucciones de 1443, 1447 y 1461 que, una vez tocadas Cádiz y Málaga, podía continuarse bien costeando como en la ida por los puertos de la Corona de Aragón y Provenza, bien dirigiéndose directamente hacia la Toscana, a veces con la posibilidad de visitar previamente Mallorca, Valencia o Alicante. Sin embargo, no es menos cierto que cuando las galeras volvían completamente cargadas de lana inglesa la tendencia era no realizar ninguna escala entre Málaga y Porto Pisano. Pero en ningún momento se indica que los patrones tengan libertad para modificar la ruta de vuelta tocando los puertos del Magreb. El único elemento de comparación posible lo ofrecen las galeras venecianas de Poniente de cuyo convoy, según parece, a partir de mediados de siglo se separaba una galeaza a la altura de Almería, volviendo a Venecia tras haber tocado en Honein, Orán y Túnez ${ }^{34}$. Pero hasta el momento ningún otro indicio sugiere que el convoy al completo o alguna de las galeras florentinas de Poniente regresaran navegando por la costa norteafricana, objetivo por otro lado de las galeras de Berbería. La única excepción la constituyen las galeras borgoñonas alquiladas por los Medici, que en 1468 surcaban la ruta de Poniente, regresando la primavera siguiente por el sur del Mediterráneo, donde está atestiguada su presencia en Túnez y Sicilia. Sin embargo, no eran galeras propiedad de la Signoria. Más aún, no hay constancia alguna de que cuando en 1469 y 1472 vuelvan a cubrir la línea de Flandes e Inglaterra hayan regresado por el Magreb ${ }^{35}$.

El mismo registro de los gastos de las galeras de Poniente arribadas en 1467 revela otros datos de particular interés, sobre todo si se tiene en cuenta que no sobreviven registros portuarios de Cádiz en el siglo XV. En efecto, se recogen los derechos de anclaje pagados en el puerto. Es un aspecto que reviste particular importancia, pues hasta el momento se carecía de datos en este sentido, por lo que la anotación "anchoraggio e salvocodotto e diritto di consolato a Cadice fiorini 10 larghi" resulta preciosa. Los derechos de anclaje y salvoconducto en están más cerca de los 9 florines pagados en Málaga y los 12 florines de Southampton que de los 6 florines abonados en Alicante (Chantera) ${ }^{36}$. Los manuales de mercaderías, de procedencia toscana

vos florentinos, si bien sigue abierta la polémica en torno a su utilidad y utilización real. Cf. MALLETT, Michael E.: The Florentine Galleys..., p. 224, nota 1; González ArÉvalo, Raúl: "La costa del Reino de Sevilla...", passim.

${ }^{33}$ ASF, CM, VII, fol. 71.

${ }^{34}$ Así consta en las órdenes ducales entregadas al capitán de la muda de Poniente de 1485. Cf. LÓPEZ DE Coca CASTAÑER, José E.: "Las galeras venecianas...", pp. 122-123.

35 Armand Grunzweig interpreta el registro en el mismo sentido al traducir "pour un pilote pris à Cadix pour la côte de Barbarie et jusqu'à Porto Pisano". Cf. A. Grunzweig, "Les Fonds...", p. 98. Mallett no plantea siquiera esta posibilidad. Para las galeras borgoñonas de $1468 \mathrm{cf}$. MALLETT, Michael E.: The Florentine Galleys..., p. 171.

${ }^{36}$ ASF, CM, VII, fol. 71. 
en su mayoría, apenas mencionan Cádiz. No así un manual veneciano de mediados del siglo xv, Alcune raxion per marineri, que recoge entre las "spexe se fa per li chapetani delle galie de Fiandra per tutte le schalle va" la siguiente información ${ }^{37}$ :

A Chades tti armiraio zontto al porto tti diè desmontar in tera et andar al nostro chonsollo et llui ve menerà là dove fa luogo per domandar el salvochodutto et quello se tuò per scritto; pagasse per chollui che schriverà, zoè el sanvochondutto, meza dobla. Pagasse per anchorazo in lo ditto luogo per gallia ducati 1 et per quella de misier lo chapetagno ducati 2; et sse per aventura arevassi avantti a Tarifa et quelli vollesse esser pagadi, pagè et feve dar un bollettin per non pagar un'altra volltta.

Pagasse in lo ditto luogo per tutte ducati 4.

La información del manual veneciano completa el registro de gastos de las galeras florentinas, abriendo nuevas perspectivas. En primer lugar, viene a confirmar la realidad de un uso lo suficientemente conocido como para ser incluido en un libro de mercancías véneto. Además, el texto confirma que Tarifa podía ser un punto de atraque habitual, por lo que es posible que la parada de Albizzi (también para proveerse de agua potable) bien podría haber sido imitada por los convoyes sucesivos, aunque no estuviera incluida en las órdenes oficiales.

Los derechos pagados en el puerto gaditano levantan asimismo nuevos interrogantes al mencionarse, además del anclaje y el salvoconducto, un "diritto di consolato": es conocida la presencia consular de genoveses y venecianos en Cádiz, pero carecemos de noticias sobre la existencia de un consulado florentino o la actuación de un cónsul de la nación toscana ${ }^{38}$. Sin embargo, el manual veneciano citado puede aportar algún indicio en este sentido: en el caso de las galeras venecianas el cónsul de su nación conducía al capitán de la muda adonde se solicitaba el salvoconducto, pagándose al escribano media dobla ${ }^{39}$. Dado el importante grado de participación de los mercaderes genoveses fletando mercancías para o desde Cádiz sobre las galeras florentinas, como se pondrá de relieve más adelante, así como los precedentes de mercaderes florentinos actuando camuflados como miembros de la nación genovesa, no se puede descartar que el registro florentino en realidad recogiera la actuación del cónsul genovés solicitando el salvoconducto para los toscanos.

Volviendo al diario de Luca di Maso degli Albizzi, el capitán del las galeras de Poniente revela otro de los peligros que acechaban los viajes: la piratería y el corsarismo. Efectivamente, durante su viaje tuvo dos desencuentros con la marina caste-

${ }^{37}$ Pittarello, Ornella (ed.): Alcune raxion per marineri. Un manuale veneziano del secolo XV per gente di mare, Venecia, 2006, pp. 147-148, fol. 73. La editora sitúa el manual concretamente en 14441445 (pp. 19 y ss.). Agradezco a la amiga y colega Adela Fábregas que me señalara esta información.

${ }^{38}$ Los inmensos fondos del Archivio Datini, que contienen numerosas referencias a Cádiz, tampoco hacen mención alguna, hasta donde sabemos, a ningún consulado florentino en la ciudad. Al menos, el mayor estudioso del archivo datiniano, Federigo Melis, no se hace eco de informaciones en este sentido en su amplia producción bibliográfica.

${ }^{39}$ Cabe entender que se trataba de la dobla castellana. Sobre el conocimiento del sistema monetario castellano en los manuales de mercancías cf. GonzÁlez ArÉvalo, Raúl: "La moneda castellana...", passim. 
llana debido al conflicto ocasionado por la intervención de los infantes de Aragón en los asuntos internos de Castilla. El primero de ellos tuvo lugar en Pontevedra, como recoge en una primera carta a los cónsules del mar desde Sluys el 6 de diciembre de 1429. Los hombres del arzobispo de Santiago les tendieron una trampa de la que consiguieron escapar a duras penas por los problemas que presentaban las galeras ${ }^{40}$ :

(...) La traversia ci ributtò et tornamo a Ponteveteri in Galitia, la conserva con ii timoni rotti e noi gottando a 3 sentine. Et giunti là così rotti, trovamo 2 balenieri armati di corsali et due navi, l'una di 600 l'altra di 400 botti, de' luogho. Surgemo per non potere ire altrove, et mandamo alla terra per salvocondotto et sicurtà. Rispuosono quegli della terra che manderebbono all'arcivescovo di santo Jacopo, ch'era loro signore, e che sanza sua parola non ci farebbono detto salvocondotto. (...) Parveci stare con pericolo, perché partire non potevamo, et balenieri non potevamo offendere per la stretta comessione abiamo. (...) Intanto quegli della terra malvagiamente ci mandarono certi loro huficiali, i quali per parte dell'arciveschovo loro signore ci asicurarono et proferso(no) aiuto et vettovaglie etc. Fucci necessario ritornare in detto porto et giunti che fumo, vedemo le navi et balenieri mettersi in punto per ofenderci et uno de' padroni delle navi ci mandò ad avisare et tutti gl'uomini ch'erano in quello luogho montavano con battegli in sulle navi e balenieri. Allora, veduto il tradimento, ci levamo prodegiando contro al vento e lla corente, e per ventura il vento calmò alquanto, per modo che pigliamo speranza ne' remi. I balenieri ch'erano 3 e amendue le navi ci ferono vela adosso con molti battegli de' paesani. Noi ci trovamo a vento I ${ }^{\mathrm{a}}$ tratta di balestro, mettemoci in ordine a battaglia non abandonando però i remi. Fucci ventura che uno pedoto disse sapere una via tra isole, che niuno altro di nostre galee sapeva. Aventuramoci, veduto il pericolo delle navi, e gratia di Dio uscimo di quelle isole con grande sospetto.

Ya en alta mar se encontraron los navíos del infante don Fernando de Portugal, tras lo cual las galeras prosiguieron hasta Ribadeo, en la costa cántabra, de donde eran los balleneros que les daban caza; éstos habían pedido ayuda a dos naves vizcaínas diciendo "le nostre galee avere robe di catalani nemici loro", pero éstas a su vez habían dado garantías a los florentinos. Las acusaciones contra los toscanos no acabaron allí:

(...) Et più vi trovamo uno Piero Ruissi bischaino, cugino del'uno de' 2 padroni delle navi, il quale si venne a dolere che quando Messer Agnolo Aciaiuoli fu capitano delle galee sottili, gli prese una sua nave et tolsegli molta roba, secondo suo dire, e diceva essere venuto a Firenze e non avere trovata giustitia.

Por fortuna para los toscanos llegó a puerto la flota portuguesa, con la que acordaron defenderse mutuamente de cualquier ataque gracias a las relaciones amistosas

${ }^{40}$ Ofrecemos un extracto resumido con el contenido más relevante. Para la carta completa cf. MALLETT, Michael E.: The Florentine Galleys..., pp. 241-246. Para el conflicto entre Juan II y los infantes de Aragón nos remitimos al estudio ya clásico de Benito Ruano, Eloy: Los infantes de Aragón, Madrid, 1952. 
iniciadas entre los dos Estados. De hecho, Albizzi supo que los marinos castellanos tenían órdenes de seguir al convoy florentino hasta Inglaterra, habiéndose lamentado el arzobispo de Santiago por haber dejado escapar semejante botín. Además, las naves vizcaínas finalmente habían accedido a asaltar las galeras florentinas con la sospecha de que transportaban mercancías catalanas, pero la fortaleza del convoy unido a la flota portuguesa les hizo desistir de sus propósitos. Con este motivo el capitán sugirió: "forse non sarebbe male che lla Signoria scrivessi a' re di Castiglia dogl(i)endosi di questo, però che i balenieri e navi erano di sue terre e ll'arciveschovo è suo huomo"41.

La razón de que Albizzi expusiera tan detalladamente los desencuentros ocurridos en tierras gallegas y cántabras la ofrece un poco más adelante en la carta:

(...) v'ò scripto sì lungho processo come di sopra ò detto perché sapiate che per tutte le terre de' re di Spagna i vostri legni saranno malsicuri, così da paesani, potendo, come da' corsali, che grande quantità se ne truova, et però bisogna ci si proveggha et massimamente perché nel nostro ritorno i corsali saranno tutti fuori, et simile molte galee sottili et balenieri et navi che s'armano in Sibilia per la guerra de' catalani, et dura in tereno di Spagna da Cartagena insino in Inghilterra, che non trovate luogho per voi sicuri salvo Portogallo.

Tres días más tarde enviaba otra nueva carta a los Cónsules del Mar resumiendo los hechos en tierras castellanas y avisando del peligro para el viaje de regreso de la acción de los corsarios, que temía más aún dado que las mercancías cargadas en Inglaterra y Flandes hacía las galeras más valiosas que a la ida ${ }^{42}$. Sin embargo, a pesar de la gran tensión vivida cuando en marzo de 1430 dos galeras castellanas preguntaron a los florentinos cerca de Cádiz la nacionalidad del convoy, los toscanos realizaron el tornaviaje por aguas ibéricas sin mayores incidentes ${ }^{43}$ :

${ }^{41}$ Aparentemente las galeras de 1429 fueron las primeras florentinas en tocar Lisboa. Albizzi, acreditado como embajador ante el rey de Portugal, negoció concesiones comerciales. La flota del infante don Fernando llevaba a la infanta Isabel a Borgoña para el matrimonio que debía contraer con el duque Felipe el Bueno. Los Cónsules del Mar florentinos informaron posteriormente que habían solicitado a la Señoría que protestase ante el rey de Castilla, como comunicaron a Albizzi en una carta que Mallett transcribe: "Et tutto abbiamo fatto noto a' nostri Magnifici Signori e a' loro collegii, et per loro s'è deliberata lettera al re di Castiglia la quale mandiamo per uno fante proprio". MALLETT, Michael E.: The Florentine Galleys..., pp. 85; 244 y nota 1; 276. Desconocemos el resultado de la iniciativa florentina, aunque lo cierto es que las galeras, hasta donde se sabe, no volvieron a tocar las costas gallegas.

${ }^{42}$ Ibidem, pp. 247-249. Reproducimos el pasaje que nos interesa: “(...) Apresso fusti avisati come a Ponteveteri in Galitia dell'arciveschovo di santo Iacopo et sotto sua fidanza et ordine, tre balenieri et due navi grosse ci vollono pigliare di sua volontà et favore, dicendo noi avere robe de catalani nemici del loro re; et però per questa resta pocho a dire, se non ricordarvi del provedimento nel tornare, che come v'è per me stato scripto, alla primavera saranno fuori molti balenieri et navi et galee armate che s'armano in Sibilia per la guerra de' catalani, e 'l simile si deve credere faranno i catalani co' loro navilii. Et sapete che queste sono due nationi atte a torre la roba dove la possono trovare, et queste galee sono tenute più ricche ancora che non sono et ànno l'entrata di dire ciaschuno di volere certificarsi se noi abbiamo roba di loro nemici".

${ }^{43}$ Ibidem, p. 268. 
Venerdì adì 10 marzo, a ora di nona passata, essendo l'aqua piene, uscimo da Silvis con bonaccia, et col nome di Dio pigliamo la via di Cadisi. La sera circa ore 23 avemo vista di ii galee sottili da levante, et nel fare della nocte si trovarono con noi. Domandarono che galee noi eravamo et noi loro, senpre colle balestre cariche et in punto da zuffa. Loro non volevano dire chi fussino né noi prima di loro, né essi levavano bandiere né noi. Infine dissono e[sse]re galee di Castiglia, et allora rispondemo essere di Firenze.

Domandaro di nuove noi et noi loro. Noi senpre seguimo nostro viaggio, et loro si tornarono la via di terra et chosì a una ora di nocte o circha ci partimo l'uno dal'altro. Avemo vista di ii navi in mare le quali stimavamo essere le nave dell'aringhe e una de' vinitiani ch'era stata a Lisbona con noi, et così dicemo alle galee sottili che cci domandarono che navi quelle erano, che l'una era fiorentina e l'altra vinitiana.

Es probable que las galeras florentinas salieran del trance con relativa facilidad porque la flota que se estaba armando en Sevilla no estaba aún operativa. De hecho, la impaciencia del almirante don Fadrique, tío de Juan II de Castilla, provocó que se hiciera a la mar con la mitad de los navíos previstos aquella misma primavera. Esta flota castellana fue la que cuatro meses depués, en julio de 1430, inspeccionó las galeras venecianas de Poniente en busca de mercancías catalanas ${ }^{44}$.

Tenemos nuevas noticias de acciones corsarias en julio de 1441 gracias a un protocolo notarial firmado en el Castil de Genoveses de Málaga ${ }^{45}$. En él se relata que, a la vez que las dos galeras florentinas de Poniente atracaban en el puerto de Cádiz, lo hacían también "due naves corsalium catalaneorum". El genovés Francesco Vivaldi, que había cargado mercancías en el puerto de Southampton para ser entregadas en Cádiz a su compatriota Luciano Marruffo, creyendo que las naves catalanas eran genovesas, subió a ellas a través de una pasarela y fue hecho prisionero y retenido junto con la pasarela y dos remeros. Los catalanes

venerunt cum quadam barca ad galeas dicendo domino capitaneo quod dare deberet et consignare eis omnes mercantias et robbas quorumcumque ianuentium aliter tractarent eis ut inimici et cetera et non poterit ipse dominus capitaneus habere voluntatem dicti domini Francisci cum dicte naves super dictis galeis extendere vellent quoddam tonum cuiusdam navette que erat in dicto portu et facerent aliis demostrationem quod preliarent dictis galeis propterea dominus et patroni preceperunt cum dictis galeis recedere de dicto portu.

Lo confirma de nuevo el testimonio de Gregorio Cattaneo más adelante en el mismo protocolo:

${ }^{44}$ Se trata de un hecho que recogen tanto fuentes venecianas -la Cronaca Morosini- como castellanas -la Crónica de Juan II de Castilla -. Cf. LANE, Frederic C.: "Andrea Barbarigo, mercante di Venezia, 1418-49”, en isdem, I mercanti di Venezia, Turín, 1982, p. 49; López de Coca Castañer, José Enrique: "Las galeras venecianas...", p. 124.

${ }^{45}$ ASF, NA, 9449, s.f., 25-VII-1441. Agradezco al amigo y colega Sergio Tognetti que me indicara la existencia del registro. 
cum dictum portum Cadix postquam dicte galee applicaverint primo et ante omnia requisivit de capitana omnes mercatores habentes mercantias pro dicto loco quod ipsas cito exorerarent et dictus Lucianus dicebatur abesse a dicto loco statim due naves corsalium suprascriptum portum Sibi(li)e aplicuerunt inter alias pravas demostrationes requisiverunt mercantias et robbas ianuensium prius retentas quodam domino Francisco Vivaldi cum scifo et duobus portulatis galee conserve eunte ad dictas n(aves) et similiter aliis ianuensibus euntibus et extenderunt quoddam tuonum cuiusdam navette que erat in portu iuxta galeas pro preliare cum dictis galeis quapropter pro salvamento galearum et mercantiarum precepit recedere dictus dominus capitaneus et recesserunt et applicuerunt portu Malice.

Finalmente, las galeras atracaron en el puerto de Málaga, donde miembros de la colonia genovesa recibieron las mercancías de Francesco Vivaldi. Las florentinas no fueron las únicas que sufrieron las maniobras catalanas en busca de mercancías genovesas, hay noticias de mercaderes venecianos afectados en Valencia ${ }^{46}$.

Dado el papel de medio de transporte desarrollado por las galeras estatales de Florencia, en las que se embarcaban mercancías por cuenta de comerciantes toscanos, pero también de genoveses, venecianos y catalanes, cabe suponer que este episodio de 1441, en el que corsarios catalanes buscaban confiscar productos de genoveses, no sería aislado. En realidad, no se trata más que de otro episodio de la rivalidad secular entre la Corona de Aragón y la República de Génova, en guerra abierta en esos momentos - como en gran parte del reinado de Alfonso el Magnánimo, por otra parte-. Tampoco se puede descartar que la acción se encuadre dentro de un marco de represalias frente a los abusos que los ligures cometían con los catalanes en territorio nazarí, con la connivencia de las autoridades granadinas. Sin embargo, extrañamente, no se se han hallado más noticias en este sentido ${ }^{47}$.

Como último apunte sobre la incidencia del corso, cuando las galeras de Poniente recalaron tres días en Sanlúcar de Barrameda en julio de 1461, los patrones enviaron un escribano a Sevilla. Dado que Angelo Spini no aporta más datos, cabría pensar que quizás acudió a solicitar alguna clase de salvoconducto, pues "dichono il Villamarina è a Chartagenta (sic)", si bien "io credo che non sia chorsale"48.

\section{LAS GALERAS DE BERBERÍA}

Los comienzos de la línea de Berbería son un tanto confusos en comparación con los de las galeras de Poniente ${ }^{49}$. Los primeros testimonios sobre el funcionamiento de

${ }^{46}$ Entre 1441 y 1443 el mercader veneciano Luigi di Merchanovo tuvo que hacer frente a una reclamación del procurador fiscal del rey en Valencia por 10 fardelli de seda y 8 bayuls (sic) de plata embarcados en la galera patroneda por Giovanni Moro porque se creía que era mercancía de genoveses. Cf. Igual LuIs, David: Valencia e Italia ..., p. 111, nota 88.

${ }^{47}$ Cf. Salicrú i Lluch, Roser: "Manifestacions i evolució de la rivalitat entre Gènova i la Corona d'Aragó a la Granada del segle xv, un reflex de les transformacions de la penetració mercantil", Acta historica et archaeologica mediaevalia, 23/24 (2002-2003), pp. 575-596.

${ }^{48}$ ASF, MAP, X, 211. Ver Apéndice.

${ }^{49}$ Para las galeras florentinas de Berbería cf. Mallett, Michael E.: The Florentine Galleys..., pp. 72-75. 
esta ruta provienen de 1447, pero no hay noticias de que se superara el Estrecho de Gibraltar hasta noviembre de 1458, cuando se menciona el envío de una sola galera que debería partir de Porto Pisano el mes de septiembre siguiente, tocando un par de puertos entre Niza y la riviera genovesa - a elección del conductor- para dirigirse a Túnez directamente con posterioridad; desde el puerto hafsí navegaría per costeriam hacia el oeste, pudiendo fondear en Almería y Málaga y atravesar el Estrecho de Gibraltar hasta Cádiz y Sanlúcar de Barrameda, para regresar a continuación siguiendo la misma ruta, con orden expresa de no descargar mercancía alguna entre Túnez y Porto Pisano ${ }^{50}$.

Cabe pensar que la ruta de 1458 tuvo buena aceptación, pues estas mismas órdenes se vieron desarrolladas al año siguiente. Los capitoli del viaje de Berbería de 1459 preveían que en vez de una sola galera como hasta el momento en el futuro partiera un convoy integrado por dos naves. Al igual que el año anterior, se evitaba el paso por las costas provenzales, limitando la presencia del convoy al norte de Porto Pisano a dos localidades -a elección de los patrones y conductores- a este y oeste respectivamente en la riviera de Génova, deteniéndose un máximo de tres días en cada una; de allí se dirigiría directamente hacia Túnez (doce días), desde donde seguiría la ruta a Bona (tres días), Collo (tres días), Bujía (tres días), Argel (tres días), Orán (seis días), Honein (tres días), Almería (cinco días), Alcudia (tres días), Málaga (tres días), Cádiz (dos días) y Sanlúcar de Barrameda (doce días). La vuelta se realizaría siguiendo el recorrido inverso hasta Túnez, y de ahí directamente a Porto Pisano, pudiendo visitar antes de arribar a las costas toscanas un solo puerto en la riviera ligur ${ }^{51}$.

Las órdenes de 1458 y 1459 son las únicas que prevén el paso del Estrecho, especificando las segundas una escala de dos días en Cádiz, mientras que en Sanlúcar de Barrameda, final del trayecto de ida, las galeras podrían detenerse doce días. Es posible que se diera más importancia a Sanlúcar por su mayor cercanía con Sevilla, preservándose Cádiz para el comercio de las galeras de Poniente, de forma que las dos rutas no se perjudicaran mutuamente. Esta explicación cobra sentido si se recuerda que la Señoría florentina había practicado esta política con anterioridad, por ejemplo, al intentar preservar el comercio de la ruta de Cataluña-Sicilia de la competencia que ejercitarían en los puertos catalano-aragoneses la presencia de los convoyes de las galeras de Poniente y Berbería. Pero además se da la circunstancia de que los encantes de las galeras venecianas de 1462 preveían igualmente una parada breve en Cádiz y otra de veinte días en Sanlúcar, donde está constatada la presencia de la muda de Berbería ya en 1442, mientras que la muda de Poniente recalaba preferentemente en Cádiz $^{52}$. Es más, las galeras venecianas dejaron de cruzar el Estrecho precisamente a partir de 1462, cuando se multiplicaron las escalas en el Magreb. Del mismo modo, no tenemos ninguna confirmación de que las florentinas volvieran a hacerlo después de 1461. Más aún, a diferencia del convoy véneto, y contrariamente a lo que deja en-

\footnotetext{
${ }^{50}$ ASF, CM, III, fol. $122 v^{0}, 15-X I-1458$.

${ }^{51}$ ASF, CM, III, fols. $124 \mathrm{y} \mathrm{v}^{\mathrm{o}}$.

52 Cf. López de Coca Castañer, José Enrique: "La "muda” de Berbería...”, pp. 365-367.
} 
tender Michael Mallett, no hay constancia de que las galeras florentinas de Berbería llegaran a remontar en algún momento el Guadalquivir ${ }^{53}$.

Efectivamente, la carta remitida por el patrón Angelo Spini señala claramente que las dos galeras de Berbería llegaron a Sanlúcar de Barrameda el 4 de julio, en conserva con una nave genovesa con capacidad de 1800 toneles y otra más pequeña de 1000, incidiendo en otro aspecto práctico de la navegación de línea, la agrupación con navíos de otras nacionalidades para mayor seguridad del viaje. Tres días más tarde, el 7 de julio, arrivaban las tres de Poniente acompañadas por dos galeras del catalán Galcerán de Requesens, dos naves de 1200 y 700 botte de capacidad respectivamente, y una carabela. Spini acudió a visitar a los patrones de Poniente, que le preguntaron cuánto tiempo tenía previsto quedarse porque querían "entrare in deta chonserva". Como respuesta les dio lo que preveían las órdenes (12 días), aunque en realidad estuvieron más tiempo, pues la carta está fechada el 18 de julio e informa que tienen previsto partir el 21, después de 17 días en el puerto. Resulta llamativa la solicitud de regresar en el mismo convoy porque las órdenes de Berbería de 1459 preveían el regreso por Túnez. De hecho, el otro patrón, Piero di Lutozzo Nasi, se ausentó "per chonprare bischotto, polvere da bonbarda e lance e altre chose abisongnano avendo a ritornare in Barberia", y Spini pedía a los Medici que les mandaran información sobre la posición de las galeras de Renato de Anjou a Piombino (el principado de los Appiani en el sur de la Toscana) o a un indeterminado chavo Chorsica $^{54}$. El peligro corsario era evidente y la situación complicada, como se lamenta amargamente Spini, que llega a escribir incrédulo que les tratan mejor los musulmanes que los cristianos $^{55}$ :

e' nostri nemici chonmincandosi per una à schierati e' provenzali, viniziani, chatalani, bischaini, portochallesi. E hora ultimamente i fiorentini ci son chontro; parmi tropa grande disgrazia che posiamo dire che da' mori abiamo aùto insino a quivi milgliore chonpangnia sino che da crestiano, sia di tutto lodato e ringraziato Idio e piac(i)ali di ritorno ristorarci e per tutto mandarci a salvamento.

De hecho, fue precisamente la amenaza de la piratería en el Mediterráneo occidental la que en última instancia provocó la decisión en noviembre de 1462 de

${ }^{53}$ Michael Mallett señala la permanencia forzosa del convoy de Berbería durante quince días "off Seville" debido a acciones corsarias. En realidad su interpretación se debe a un error de lectura de la carta remitida desde Sanlúcar, donde en realidad se encontraban y permanecerían más de quince días, siguiendo las instrucciones oficiales. Cf. Mallett, Michael E.: The Florentine Galleys..., pp. 74 y 165. Ver Apéndice.

${ }^{54}$ ASF, MAP, X, 211. Ver Apéndice.

${ }^{55}$ Ibídem. Ése verano fue prolijo en actividades corsarias: Jacques Heers ha recogido diversos incidentes a propósito de la participación francesa en el conflicto secular entre Génova y la Corona de Aragón; así, algunas naves genovesas fueron capturadas por las galeras francesas, y hay noticias de varias más que quedaron inmobilizadas en Córcega por miedo a correr la misma suerte. Como represalia, Giacomo Spinola capturaba en Cádiz una galeazza gala. Cf. HeErs, Jacques: "Entre Gênes et Barcelone: Les ports français du Languedoc. Guerre, commerce et piraterie (1380-1450 environ)", Anuario de Estudios Medievales, 24 (1994), p. 522. 
que no partiera el convoy de Berbería ${ }^{56}$. Poco después, en enero de 1463 , se decidió mandar una sola galera siguiendo básicamente la ruta detallada para la Barberia alta de 1447, es decir, descendiendo por Nápoles y Sicilia hasta Túnez y vuelta. Sin embargo, en esta ocasión parece claro que la opción de no detenerse ni en otros puertos magrebíes ni en los nazaríes y los castellanos al otro lado del Estrecho obedeció a una mera cuestión logística: estando programadas las galeras de Cataluña para junio, las de Romania para julio y las de Poniente para agosto o septiembre, no había tiempo para que el convoy de la Berbería de Poniente pudiera realizar todo su recorrido, para el que solía emplear en torno a cuatro meses ${ }^{57}$. Todo intento de poner en marcha la ruta de Berbería de Poniente ese mismo año fue abandonado definitivamente en noviembre de 1463, cuando el Consejo tomó la decisión de la "subspensio viatici Barberie (...) per hoc anno", y no hay más referencias a esta línea entre 1466 y 1478.

En definitiva, queda claro que la línea tuvo una vida discontinua como ruta independiente, en la que Cádiz y Sanlúcar de Barrameda tuvieron una presencia alterna, apenas constatada entre 1458 y 1461. En consecuencia, no parece errado considerar que la ruta de Berbería tuvo una importancia muy limitada a la hora de articular la presencia toscana en el suroeste peninsular.

\section{CÁDIZ EN LOS FLETES DE LAS GALERAS MERCANTILES DE FLORENCIA}

La organización estatal de las galeras florentinas incluía instrucciones muy detalladas para los notarios que iban a bordo de cada una de las naves con la misión de registrar el movimiento de mercancías y evitar el fraude en consecuencia. Se trata de una información especialmente útil que permite estudiar la circulación de artículos. Aunque no siempre haya constancia de que se hayan llegado a transportar todos los bienes previstos, no sería erróneo suponer que, presumiblemente en cantidades menores, habrían estado igualmente presentes en el comercio de las naves.

Michael Mallett ha señalado diferencias entre los fletes incluidos en las órdenes de 1442 y los de 1461: a veinte años de distancia, la revisión que tuvo lugar a principios de la década de 1460 muestra que si de una parte habían dejado de transportarse pocos bienes, de otra las cargas impuestas sobre cada uno de ellos llegaron a reducirse en algunos casos a la mitad. Con todo, se trata de un aspecto sobre el que no nos detendremos, pues en ningún caso los precios de los fletes en 1442 se refieren a los puertos de la Corona de Castilla ${ }^{58}$.

Los fletes de Porto Pisano a Flandes e Inglaterra muestran la mercancía que, en teoría, iba todo el viaje de ida a bordo del convoy, sin que se comerciara con ella en las escalas intermedias. Un análisis somero revela que los productos italianos que

${ }^{56}$ ASF, CM, III, fol. 155, 24-XI-1462.

${ }^{57}$ ASF, CM, III, fol. $155 \mathrm{v}^{\circ}, 4-\mathrm{I}-1463$.

${ }^{58}$ Cabe recordar en los fletes de Porto Pisano a Collioure y toda Cataluña (entiéndase Corona de Aragón) la mención de "ghuadi per insino in Spagna, il centinaio a peso, fiorino uno", dando a entender que las galeras florentinas podían llevar pastel hasta los puertos castellanos, con toda probabilidad Cádiz, como especifica también de manera más concreta la disposición para "malvagie per insino a Cadis, la botte, fiorini cinque". ASF, CM, IV, 6, fol. 10. 
encontraban mayor salida en el comercio de las galeras de Poniente estaban relacionados con la potente industria textil del centro de la Península Italiana, no sólo la Toscana, sino también la proveniente de territorios vecinos como la Romaña, con los velos de Bolonia y Perusa. Pero sin duda la palma se la llevaba la industria textil florentina, los paños laneros y los séricos ${ }^{59}$, cuyo valor destaca por encima de las materias primas contempladas.

Para nuestro propósito resulta más interesante señalar que también se contemplaban fletes para las escalas intermedias de la ruta de Poniente: de Marsella, Portle-Bouc y Aigües Mortes para toda Cataluña, o de Marsella y toda Cataluña para Flandes e Inglaterra. En este contexto la vocación de medio de transporte de las galeras florentinas encuentra una de sus expresiones más evidentes en los "Noli di tutta la Catalogna per Almeria, Malaga et Cadis". En 1461 estaban previstas escalas en San Felíu de Guixols o Barcelona, Valencia, Denia, Jávea y Alicante; en cualquiera de ellas se pagarían 13 sueldos y 4 dineros por cada pieza de paño embarcada con destino a los puertos nazaríes o el gaditano, mientras que por arroz, queso, nuez de galla, tártaro, "y otra mercancía de poco valor" se abonarían 6 sueldos y 8 dineros por cántaro ${ }^{60}$.

Cádiz se revela como el puerto más importante para las galeras florentinas en el sur ibérico, a juzgar por la extensión de los "Noli di Porto Pisano per Cadis", recogidos en el Cuadro 1. Una comparación con los fletes que contiene el gravamen de los artículos enviados desde Porto Pisano hasta Flandes e Inglaterra revela que los fletes para Cádiz desde el puerto toscano eran básicamente los mismos, variando simplemente el alcance de los derechos, más baratos que en el destino final. Más aún, si se comparan con los previstos para Marsella, Port-de-Bouc y Aigüesmortes de una parte, y los de "toda Cataluña" (San Felíu de Guixols, Barcelona, Valencia, Denia, Jávea y Alicante) de otra ${ }^{61}$, se observa que el puerto gaditano recibía la misma consideración que las escalas antes nombradas, reforzando su papel como principal puerto del sur peninsular. Respecto al destino final en el Mar del Norte todos ellos se distinguen por contemplar la exportación de libros de texto; para Cádiz estaba prevista además la exportación de grano y todo tipo de forrajes.

\section{Cuadro 1: Fletes de Porto Pisano para Cádiz en 1461 ${ }^{62}$}

\begin{tabular}{|l|l|c|c|c|}
\hline Mercancía & Medidas $^{\mathbf{6 3}}$ & Florines & Sueldos & Dineros \\
\hline Especias de toda clase & Il centinaio & 1 largho & & \\
\hline Plata, oro hilado y joyas & A valuta per centinaio & 1 & 10 & \\
\hline
\end{tabular}

59 Se trata de una industria que ha producido una abundante bibliografía específica. Nos remitimos a las siguientes monografías: HosHino, Hidetoshi: Industria tessile e commercio internazionale nella Firenze del tardo Medioevo, Florencia, 2001; Tognetri, Sergio: Un'industria di lusso al servizio del grande commercio. Il mercato dei drappi serici e della seta nella Firenze del Quattroceto, Florencia, 2002.

${ }^{60} \mathrm{ASF}, \mathrm{CM}, \mathrm{IV}, 6$, fol. 12.

${ }^{61}$ ASF, CM, IV, 6, fols. $13 \mathrm{v}^{\mathrm{o}}-14$.

62 Ibidem, fol. $14 \mathrm{y} \mathrm{v}^{\mathbf{0}}$.

${ }^{63}$ Como norma general la expresión il centinaio abrevia il centinaio a peso, es decir, que el gravamen se establece por cada 100 libras de peso, en contraposición a il centinaio ad valorem. 


\begin{tabular}{|c|c|c|c|c|}
\hline Mercancía & Medidas $^{63}$ & Florines & Sueldos & Dineros \\
\hline $\begin{array}{l}\text { Velos de Perusa, velos de Bolonia, tafe- } \\
\text { tanes }\end{array}$ & $\begin{array}{l}\text { La libbra s'istimi du- } \\
\text { cati } 5 \text { et paghi per cen- }\end{array}$ & 4 & & \\
\hline Fustanes de toda clase & 1 bala de 15 piezas & 4 & & \\
\hline Mercancías y armaduras & 1 bala de 250 libras & 4 & & \\
\hline Espadas & 1 caja de 150 lamas & 5 & & \\
\hline Papel & 1 bala de 12 lisime & & 15 & \\
\hline Albayalde & 1 barril & & 6 & 8 \\
\hline Peletería, bassette & 1 bala de 250 libras & 2 & 10 & \\
\hline Paños florentinos de San Martín sin gra- & 1 pieza & 1 & 5 & \\
\hline Paños lucchesini y paghonazi $i^{64}$ & 1 pieza & 1 & & \\
\hline Paños di garbo & 1 pieza & & 15 & \\
\hline Vitriolo, azúfre, tártaro & 1 tonel de 250 libras & & 13 & 4 \\
\hline Acero & 1 bala de 150 libras & & 10 & \\
\hline $\begin{array}{l}\text { Paños de seda de color excepto carmesí, } \\
\text { sin oro, se estime la libra a } 4 \text { ducados }\end{array}$ & Il centinaio & 3 & & \\
\hline $\begin{array}{l}\text { Paños recamados, imperiales, baldaqui- } \\
\text { nes, terciopelos de hilo, se estime la libra } \\
\text { a } 6 \text { ducados }\end{array}$ & Il centinaio & 3 & & \\
\hline $\begin{array}{l}\text { Paños de seda carmesí, paños rasos de } \\
\text { oro, es decir, damascos, brocados, se es- } \\
\text { time la libra a } 5 \text { ducados }\end{array}$ & Il centinaio & 3 & & \\
\hline Alumbre, nitrato & 1 tonel de 250 libras & & 15 & \\
\hline Azúcar de todas clases & Il centinaio & & 10 & \\
\hline Pastel & Il centinaio & & 3 & \\
\hline $\begin{array}{l}\text { Malvasía, moscatel, vino corso, razzese, } \\
\text { aceite de laurel, aceite común }\end{array}$ & 1 tonel & 3 & & \\
\hline Algodón en bruto & Il centinaio & & 10 & \\
\hline Algodón hilado & Il centinaio & 1 & & \\
\hline Azafrán & Il centinaio & 5 & & \\
\hline Libros de estudiantes & Il centinaio & 2 & & \\
\hline Grano y todo tipo de forrajes & 1 moyo $^{65}$ & 1 & 6 & 8 \\
\hline
\end{tabular}

Siguiendo con el papel destacado otorgado al puerto gaditano, el único de los puertos del meridión ibérico en el que oficialmente las galeras mercantiles cargaban mercancías hacia Flandes e Inglaterra era Cádiz. Así, los "Noli da Cadis per Fiandra et Inghilterra" de 1461 preveían que en el puerto gaditano se pudieran embarcar seda (6 florines), cera (1 florín) y mercurio (3 sueldos di grossi), siguiendo medidas de

${ }^{64}$ Los panni lucchesini, tejidos con la mejor lana inglesa y teñidos con más grana de la habitual, recibirían su nombre probablemente, a decir de Hidetoshi Hoshino, de la semejanza con ciertos paños de seda teñidos con grana. El paño bianco de lana, una vez teñido con grana oriental finamente molida (polvere di Levante) recibía el nombre de lucchesino, mientras que si se empleaba grana de origen ibérico (polvere di Ponente) se denominaba pagonazzo. Cf. HOSHINO, Hidetoshi: Industria tessile, pp. 31-34.

${ }^{65}$ El manual compilado por Bernardo da Uzzano en Florencia en 1442 señala que el moggio pisano equivalía a 13'5 fanegas en Sevilla. Cf. PAGNINI DEL VENTURA, Giovanni Francesco: Della decimae delle altre gravezze imposte dal Comune di Firenze; Della moneta e della mercatura de'forentini fno al secolo XVI. Tomo quarto contenente la pratica della mer catura scritta da Giovanni di Antonio da Uzzano nel 1442, vol. II, Lisboa y Luca 1786, p. 175 
Brujas (il centinaio di Bruggia), lo que daría a entender que éste era el destino final, además de aceite y vino de toda clase (5 florines el tonel) ${ }^{66}$.

La primacía gaditana en el viaje de ida se reduce en el de vuelta, a juzgar por la consideración igualitaria que recibía Cádiz junto con Málaga y Almería, destinatarios por igual de los mismos artículos procedentes de Inglaterra, como confirmaría la moneda esterlina y la medida londinense (Cuadro 2).

\section{Cuadro 2: Fletes de Flandes e Inglaterra hacia Cádiz, Málaga y Almería en 1461 ${ }^{67}$}

\begin{tabular}{|c|c|c|c|}
\hline Mercancía & Flete a Cádiz & Flete a Málaga & Flete a Almería \\
\hline Paños, il centinaio de Londres & 7 sueldos esterlinos & 8 sueldos & 9 sueldos \\
\hline $\begin{array}{l}\text { Artículos de lana, tapices, sayas de } \\
\text { toda clase, il centinaio de Londres }\end{array}$ & 7 sueldos esterlinos & $\begin{array}{l}\text { esterlinos } \\
8 \text { sueldos } \\
\text { esterlinos }\end{array}$ & $\begin{array}{l}\text { esterlinos } \\
9 \text { sueldos } \\
\text { esterlinos }\end{array}$ \\
\hline $\begin{array}{l}\text { Plomo y estaño, el pan de } 6 \text { a } 7 \\
\text { cántaros }\end{array}$ & 3 sueldos esterlinos & & $\begin{array}{l}3 \text { sueldos y } \\
4 \text { dineros esterlinos }\end{array}$ \\
\hline $\begin{array}{l}\text { Estaño trabajado, } 1 \text { carratello de } \\
4 \text { cántaros }\end{array}$ & $\begin{array}{l}6 \text { sueldos y } \\
8 \text { dineros esterlinos }\end{array}$ & & $\begin{array}{l}3 \text { sueldos y } \\
4 \text { dineros esterlinos }\end{array}$ \\
\hline
\end{tabular}

Cuadro 3: Fletes de Cádiz, Málaga y Almería para Porto Pisano en 1461 ${ }^{68}$

\begin{tabular}{|l|l|c|c|c|}
\hline Mercancía & Medida & Florines & Sueldos & Dineros \\
\hline Seda & 1 cántaro & 10 & & \\
\hline Grana & Il centinaio & 2 & 12 & \\
\hline Cera & 1 cántaro & & & \\
\hline $\begin{array}{l}\text { Cueros spagnoli de } \\
\text { Sevilla, } \\
\text { Jerez, Cádiz, }\end{array}$ & 6 piezas & & & \\
$\begin{array}{l}\text { Sanlúcar de Barra- } \\
\text { meda }\end{array}$ & & 1 & & \\
\hline Cueros portogallesi & 7 piezas & & & \\
\hline Cueros galletiane & 8 piezas & 1 & & \\
\hline Cueros berberiscos & 9 piezas & 1 & & \\
\hline Atún, sebo & 1 cántaro & 1 & & \\
\hline Mercurio & 1 bigliuono & & & \\
\hline Cinabrio & il medesimo pregio d'altrettanto peso & & 13 & 4 \\
\hline
\end{tabular}

De la misma manera, los fletes de artículos previstos en los puertos del sur peninsular (Cuadro 3) incluyen los más conocidos en los mercados internacionales: seda,

${ }^{66} \mathrm{ASF}, \mathrm{CM}, \mathrm{IV}, 6$, fol. $12 \mathrm{v}^{\mathrm{o}}$. Es probable que los soldi 3 di grossi se refieran al gros tournois flamenco, creado sobre el modelo del gros tournois francés, dividido asimismo en sueldos; la moneda gala se cambiaba en Sevilla desde el siglo XIV. Cf. GonzÁlez Arévalo, Raúl: "La moneda castellana...", p. 274.

${ }^{67} \mathrm{ASF}, \mathrm{CM}, \mathrm{IV}, 6$, fol. $12 \mathrm{v}^{\mathrm{o}}$. Se trata de los mismos productos previstos también en los "Noli di Fiandra et Inghilterra per Catalogna".

${ }^{68}$ ASF, CM, IV, 6, fol. 13.

${ }^{69}$ Giorgio di Lorenzo Chiarini menciona a medidados del siglo Xv la exportación de mercurio desde Sevilla medido en bugliuoli, que equivalía a 5 arrobas. Cf. BORLANDI, Franco (ed.): El libro di mercatantie et usanze de' paesi, Turín 1936, p. 129. 
grana, cera y cueros. El mercurio castellano se encontraría exclusivamente en Cádiz. Por su parte, el coste mucho más elevado del flete de cántaros de seda responde sin duda al prestigio de la seda nazarí, que alcanzaba buenos precios en los mercados del centro y norte de la Península Italiana ${ }^{70}$.

Desafortunadamente, los "Noli da Porto pisano per Tunisi et tucta la Barberia insino in Cadis" de 1459 no especifican los fletes para cada escala ${ }^{71}$. Sin embargo, no es erróneo suponer que en Porto Pisano se embarcaban con destino al Magreb todos los productos textiles (paños ingleses y florentinos, fustanes, etc.) y el papel, así como el aceite y la malvasía -el vino presumiblemente para Cádiz y Sanlúcar de Barrameda, no para los puertos magrebíes ni nazaríes- tártaro, azúfre y albayalde. Se trata de productos que las galeras florentinas también transportaban hacia los puertos de Provenza, la Corona de Aragón, Cádiz, Flandes e Inglaterra en la ruta de Poniente. En los puertos norteafricanos era embarcada sin lugar a dudas la laca y el tártaro árabe, las plumas de avestruz, los dátiles y los cueros berberiscos, cuyo destino podía ser tanto el sur ibérico como la Toscana. Por su parte, en las escalas nazaríes y Cádiz serían embarcados los cueros spagnoli, los ghalitiane y los portoghallese, así como la seda, la grana y la cera, aunque estos dos últimos productos también se encontraban abundantemente en el Norte de África. El queso, sin embargo, es probable que fuera embarcado en Sicilia.

\section{FLORENTINOS Y GENOVESES: EL COMERCIO DE LAS GALERAS}

El primero de los problemas a la hora de analizar el comercio de las galeras florentinas es que subsisten pocos registros oficiales con los cargamentos, casi siempre referidos a los tornaviajes, con las mercancías llegadas a Porto Pisano, y en la mayoría de las ocasiones no se especifica su procedencia. Más aún, en el caso concreto de las galeras de Poniente, las que más información revelan sobre los puertos andaluces, muy pocas veces conocemos su papel como punto de recogida o destino de mercaderías, y no siempre coinciden con el contenido de los fletes oficiales, arrojando nueva luz -y nuevas sombras- sobre el comercio de las galeras.

Los primeros testimonios los proporciona, como no podía ser de otra manera, el diario de Luca di Maso degli Albizzi. Ya se ha hecho referencia a las dificultades en el paso del Estrecho, por lo que ahora resulta más interesante mencionar las operaciones realizadas en Cádiz. La mar gruesa impidió todo tipo de actividad el 25 de octubre, no así al día siguiente: se descargaron 400 cántaros entre las dos galeras, probablemente con parte de la fruta pasa previamente embarcada en Valencia, Mallorca y Villajoyosa. Con todo, los pilotos observaron que la galera capitana tenía un sobrepeso de 500 cántaros que harían inviable la travesía del Atlántico. Dudando entre trasladar la mitad a la galera de conserva para equilibrar los cargamentos o bien dejar parte en tierra, finalmente Albizzi, tras escuchar el consejo de parte de la

${ }^{70}$ La seda spagnola, como se denominaba comúnmente la seda nazarí, tenía un precio superior a las de otra procedencia. Cf. EdLER DE ROOVER, Florence: L'arte della seta a Firenze nel secolo XIV e XV, Florencia, 1999, p. 26.

${ }^{71}$ Previamente publicados en Amari, Michele: I diplomi arabi del R. Archivio forentino. Appendice, Florencia, 1867, pp. 66-67. 
tripulación, decidió desembarcar 175 cántaros de higos secos (zibbibo) y cerca de 40 tablones $^{72}$, a pesar de lo cual la galera capitana siguió estando más cargada que la otra. Hubiera sido interesante conocer el destino de la mercancía, es decir, si fue almacenada para recogerla al regreso - presumiblemente no fue así, al menos el diario nada dice-, o si bien fue adquirida por mercaderes, locales o extranjeros.

El descubrimiento a principios de la década de 1460 de las minas de alumbre en Tolfa, en el Patrimonio de San Pedro, y su explotación exclusiva a manos de los Medici propició a partir de entonces que las galeras florentinas transportaran enormes cargamentos del mineral en el viaje de Poniente ${ }^{73}$. En ocasiones podía ocurrir incluso que el cargamento era tan grande que ponía en riesgo la travesía por el Atlántico, como se deduce del hecho de que en otoño de 1472 las galeras borgoñonas alquiladas por los Medici -que ese año cubrían la ruta de Poniente- tuvieran que descargar 503 sacas de alumbre (habiendo tenido que dejar previamente en Italia 1.100 más) y 436 de nuez de galla en Cádiz en un navío portugués, según informaba desde Sevilla Piero Doffi la primavera siguiente. La mercancía quedó almacenada en "buon luogo a stanza del signor ducha", a cargo de un tal Giovanni di Sibilia ${ }^{74}$.

Si en la década de 1460 se produjo un cambio en las mercancías que se transportaban hacia el norte, la función primaria del viaje de Flandes e Inglaterra -asegurar el suministro de lana para la floreciente industria florentina- permaneció invariable a lo largo de toda la vida del sistema. Los registros oficiales arrojan un poco más de luz sobre el papel del litoral andaluz en el comercio de las galeras. Una vez más, Luca di Maso degli Albizzi proporciona las primeras informaciones valiosas. En febrero de 1430 el convoy florentino cargaba en Southampton lana y artículos textiles, componentes principales del cargamento, con destino a Porto Pisano, "e più balloni vi di panni di genovesi per a Calisi e Malicha caricamo in detto luogho", dando la primera información conservada sobre el papel de los mercaderes genoveses residentes en Inglaterra en el comercio de las galeras ${ }^{75}$.

La noche del 11 de marzo las galeras llegaban a Cádiz, fondeando fuera del puerto, en los bancos de arena de Las Puercas. Albizzi hizo descender a dos mercaderes genoveses, que habían embarcado en Inglaterra, para que preguntaran a sus connacionales si querían que se descargasen sus mercancías allí o en Málaga, tal como habían acordado. Finalmente continuaron hasta el puerto malagueño, donde desembarcó un mercader genovés junto con balas de estaño, pero nada se dice de los "balloni vi di panni"”7.

72 Albizzi escribe "circha 40 pezzi d'assi da stiva", que Mallett traduce como "loading planks", tablas para desembarcar, probablemente tablones para repartir y estabilizar el cargamento. Cf. MALLETT, Michael E.: The Florentine Galleys..., p. 224 y nota 2.

${ }^{73}$ Para el monopolio de los Medici sobre el alumbre de Tolfa cf. DE Roover, Raymond: Il banco Medici dalle origini al declino (1397-1494), Florencia, 1970, pp. 218-237.

${ }^{74}$ ASF, MAP, XXI, 387, 17-V-1473. Desgraciadamente no se especifica quién es el duque que facilita el almacenamiento.

${ }^{75}$ Cf. Mallett, Michael E.: The Florentine Galleys..., p. 267.

76 "Surgemo a Cadisi, fuori del porto, che si dice a' Porci. Perché 'l tenpo era frescho et buono per noi, per non ci i(n)pegnare mandamo i pedoti in terra et ii mercanti genovesi per avere lingua se volevano ivi le loro robe o a Malicha, che così avevano pattegiato, et con loro mandai Tadeo di Pionbino, per che subito tornassi indietro colla barcha et non si lasciassi tenere parole. Et così fè, per che la sera, 
Las noticias sobre los cargamentos de vuelta en 1439 y 1443 no aportan informaciones referentes a mercancías castellanas o granadinas. No así el viaje de 1444, en el que las galeras habían embarcado presumiblemente en Spagna 200 cueros, 32 balas de grana, 48 fardos de seda y 46 balas de cera ${ }^{77}$. En esta ocasión la dificultad está en interpretar el significado de Spagna: aunque en el siglo XIV había una tendencia generalizada en las fuentes italianas a identificar el vocablo con la Península Ibérica, la documentación mercantil del siglo Xv lo emplea no pocas veces de manera genérica para referirse a la Corona de Castilla ${ }^{78}$. No nos aclaran mucho más los fletes oficiales de 1461 pues, como ya se ha visto, preveían que se pudiera embarcar seda, grana, cera y cueros tanto en Cádiz como en Málaga y Almería, por lo que a falta de más datos resulta imposible dilucidar la procedencia exacta de esta mercadería.

Las informaciones de los artículos transportados por las galeras de 1448 y 1464 indican la presencia de pieles de cordero y de becerro, presumiblemente recogidos en el sur peninsular, pero nada se indica al respecto en esta ocasión ${ }^{79}$. Sin embargo, el 6 de junio de 1466 llegaban a Porto Pisano las galeras de Flandes, capitaneadas por Agostino Biliotti, con seda, grana, cera y cueros de buey y becerro embarcados, una vez más, en Spagna ${ }^{80}$. Al año siguiente las galeras de Poniente, que habían zarpado el 18 de agosto de 1466, regresaron el 7 de mayo de 1467 asimismo con lana, grana, seda, sarga, maneta morisca, cueros gruesos y doce esclavos de Spagna, además de informar que "abiamo lasciato in Chadisi e a Malicha tre balloni e balle circha 40, presumiblemente paños y grana o sarga" ${ }^{81}$. El aumento de la carga recogida entre

tramonto il sole, tornò colla barcha et co' mercanti. Et subito facemo vela et navichamo tutta nocte con vento prospero, et la mattina domenicha adì 12 , a levata di sole, ci trovamo dentro allo stretto, sopra il monte Giubeltaro in Granata, et rivedemo le dette ii navi per poppa a noi circha miglia 15. El vento era ponente et libeccio, a noi prospero et bonaccievole, et così navichamo insino a ore $22 \mathrm{o}$ circha, et surgemo a Malicha, dove scarichamo uno mercatante genovese con certi baloni di rami et stagni, et non trovando niente da carichare per la cattiva dispositione del paese, a una ora di nocte fumo spacciati per partire, che pocho rinfreschamento pigliamo". Ibidem, p. 269.

77 ASF, MAP, VII, 445, 4-VI-1444. "Charico delle ghalee di Firenze venute di Fiandra adì 4 di giugno: 1399 pocche di lana; 26 balloni, 52 balle di panni; 5 tonelli, 3 chase, 1 cresta, 1 balla di mortero; 1 balla di berretta; 3 charatelli di pannorum; 5 balle di panni d'arazo; 2 balle di piume; 11 charatelli di stagno; 20 pezi di stagno sodo; 62 pezi di pionbi; 200 chuoia; 32 balle di grana; 48 fardelli di seta spagnola; 46 balle (di) ciera". Además, se da la circunstancia de que, por una vez, se pueden comparar la lista del cargamento remitido por Giovenco della Stufa a los Medici con los registros de las aduanas inglesas. Cf. Mallett, Michael E.: The Florentine Galleys..., pp. 139-140. Mallett señala de manera errónea la presencia de "5 bales of Arras cloths", habiendo confundido la localidad flamenca en la lectura de "panni d'arazo", esto es, paños de lana.

${ }^{78}$ Cf. GonzÁlez Arévalo, Raúl: "La costa del Reino de Granada en la documentación náutica italiana (siglos XIV-XVI)”, En la España Medieval, 31 (2008), pp. 10-14.

${ }^{79}$ Cf. Mallett, Michael E.: The Florentine Galleys..., p. 140.

${ }^{80}$ El cargamento completo era el siguiente: " 2.253 pocche di lana, 84 balloni di panni, 30 balle di mercie, 26 balle di piuma, 200 pani di pionbo, 36 pani di stagno, 20 charatelli di stagno lavorato, 72 fardelli di seta spagnola, 2 balle di ghrana, 26 chostali di ciera, 583 chu(o)ia di bue, 4 balle di vitellini". ASF, CM, VII, fol. 65, 6-VI-1466.

${ }^{81}$ La carga total era: "608 pocche di lana, 109 balloni di panni, 32 fanghotti di pan, 1 balla di vitellini, 24 barili di stagno lavorato, 31 pani di stagno, 36 pani di pionbo, 53 sacche di lana di Spagna, 33 balle di ghrana, 4 fardelli di seta, 3 balle di sargie, 1 saccho di maneta morescha, 1263 quoiaia grosse di 
1466 y 1467 en la Península Ibérica durante el tornaviaje sólo puede significar una cosa: las galeras no habían partido de Inglaterra al límite de su capacidad, por lo que se había completado el cargamento en Cádiz y Málaga.

El último registro oficial que proporciona información sobre las mercancías embarcadas en el sur de la Península Ibérica se refiere a las galeras de Poniente que atracaron en Porto Pisano el 1 de septiembre de 1468. En esta ocasión transportaban los siguientes artículos embarcados en Spagna: mercurio, tártaro, cera, sarga, grana y oro de Tibico valorado en 10.000 ducados $^{82}$. La cera y la grana eran ya, a estas alturas, mercancías habituales de las galeras, algo menos la sarga. Sin embargo, comparecen por primera y única vez el tártaro -contemplado en los fletes de Berbería, pero no en los de Poniente- y el mercurio, cuya presencia se explica por la minas de Almadén, las más importantes de Europa, que exportaban por vía marítima a través de Sevilla y Cádiz a toda Europa, como se hacen eco los manuales de mercaderías de Francesco Balducci Pegolotti (primera mitad del siglo XIV) y el copiado por Giorgio di Lorenzo Chiarini en Ragusa (c. 1450) ${ }^{83}$. Respecto al oro de Tibico, también citado como oro de Tiwal o Tiber, del que en 1466 se había cargado una cantidad valorada en 40.000 ducados, desgraciadamente no tenemos más datos seriados y sistematizados, aunque, evidentemente, desempeñó un papel relevante, al menos en la década de 1460. Por otra parte, es bien conocida la posición de Cádiz en la distribución del oro africano, un comercio en el que los genoveses tuvieron un papel muy destacado ${ }^{84}$.

En consecuencia, los registros oficiales no arrojan mucha luz sobre el papel de Cádiz en el comercio de las galeras florentinas, más allá de señalar los cargamentos, generalmente de paños, que los genoveses embarcaban con destino al puerto gaditano o a Málaga, pues resulta imposible aventurar la procedencia exacta de los ar tículos de Spagna. Para ello hay que recurrir a fuentes complementarias: los registros de algunas compañías florentinas - escasos- o bien otros archivos, sin olvidar las noticias proporcionadas por mercaderes genoveses.

Así por ejemplo, W. B. Watson ha calculado a partir de los datos del Custom Accounts del Public Record Office de Londres que las galeras de Poniente que zarparon de Porto Pisano a mediados de septiembre de 1443 -y abandonaron el puerto gaditano tras realizar la preceptiva escala el 14 de diciembre de ese mismo año-fletaron entre Almería, Málaga y Cádiz aceite, jabón blanco, vino dulce, seda cruda y otros

Spagna, 12 teste bianche. Abiamo lasciato in Chadisi e a Malicha tre balloni e balle circha 40". Ibidem, fol. $67,7-\mathrm{V}-1467$.

${ }^{82}$ La carga todal incluía: " 1273 poche di lana, 67 balloni e 40 balle di panni (ilegible), 23 balle di spezinere (sic), 7 balle di paime, 416 pani di pionbo, 40 charatelli di stagni e otoni lavorati, 2 chasse di libri, 4 buglinoli d'ariento vivo, 2 farde di giome, 4 chostali di cera, 4 balle di serge, 54 balle di grana di Spagna". Ibidem, fol. 74, 1-IX-1468.

83 Evans, Allan (ed.): Francesco Balducci Pegolotti. La pratica della mercatura, Cambridge (Massachusetts) 1936, p. 270; Borlandi, Franco (ed.): El libro di mercatantie..., p. 129. Mallett, Michael E.: The Florentine Galleys..., p. 142; Grunzweig, Armand: “Les fonds...”, p. 100.

${ }^{84}$ Cf. Heers, Jacques: "Le Sahara et le commerce méditerranéen à la fin du Moyen Age", Annales de l'Institut d'Etudes Orientales, 16 (1958), pp. 247-257. Armand Grunzweig afirma que Tibico es, sin asomo de duda, una mina de oro sita en la Península porque los cargamentos desembarcados en Porto Pisano recogían las mercancías fletadas en las escalas del tornaviaje. No se plantea el origen africano del oro. Cf. Grunzweig, Armand: "Les fonds...", pp. 95 y 100. 
pocos artículos que habrían constituido el $22 \%$ del valor del cargamento desembarcado, si bien también admite que es de todo punto imposible conocer con certeza el punto exacto de embarque sin una información más precisa. En todo caso, contrastando estos datos con las tarifas oficiales de fletes de 1461, se puede deducir que el aceite, el vino y el jabón se adquirieron con toda probabilidad en Cádiz, mientras que la seda provendría del territorio nazarí. Lo que Watson no tuvo en cuenta es que las órdenes oficiales de 1443 no contemplaban parar en Almería, por lo que quizás deba señalarse Málaga exclusivamente como escala nazarí. Por otra parte, la importancia de los puertos meridionales queda reflejada al comparar ese $22 \%$ del valor del cargamento total con la aportación de Florencia (6\%), Cataluña (33\%), Valencia-Alicante $(29 \%)$ y Flandes $(10 \%)$, según se desprende de los registros ingleses ${ }^{85}$.

Un registro de la contabilidad de los Cambini recoge que en 1462 Giovanni Guidetti, mercader florentino residente en Lisboa y corresponsal de la azienda cambiniana de Pisa en Portugal, hizo cargar en Cádiz en las galeras de Poniente cuatro cajas de su propiedad, con telas diversas (terciopelos carmesí, raso verde, raso negro, damascos blancos) por valor de 19 florines (incluidos los gastos de flete). Desafortunadamente, no se especifica el destino de la mercancía ${ }^{86}$. No parece probable que hubiera muchas más actuaciones en este sentido desde Portugal, a pesar de la relación comercial fluida entre los agentes italianos presentes en Lisboa, Sevilla y Cádiz, principalmente porque las sociedades florentinas establecidas en el reino luso operaban sirviéndose de la navegación privada más que de las galeras estatales, como era el caso de los Cambini, que empleaban preferentemente naves de gran tonelaje (carracas y balleneros), propias o portuguesas. En todo caso, hasta el momento no se han hallado más indicios que modifiquen esta visión ${ }^{87}$.

Por otra parte, gracias a los registros notariales ligures conocemos que en 1445 se descargaron 120 balas de paños ingleses en Cádiz y Málaga, presumiblemente por cuenta de mercaderes genoveses en ambos casos, pues lo anotaron los recaudadores de los "Carati Vetterum". En su mayor parte se trataba de panni larghi de buena calidad, pues prácticamente no se citan balas de panni stricti, hecho avalado por otras fuentes que confirman que los paños de los almacenes genoveses en Málaga eran todos caros, estimados en 42 besantes cada uno ${ }^{88}$.

${ }^{85}$ Cf. Watson, W. B.: "The structure of the Florentine galley trade with Flanders and England in the 15th century", Revue belge de philologie et d'histoire, 39 (1961) pp. 1080 y 1088; idem, 40 (1962), p. 337.

${ }^{86}$ Cf. D’Arienzo, Luisa: "Le relazioni tra Genova e Cadice fra il XIII e il xv secolo", en González Jiménez, Manuel y Montes Romero-CAmacho, Isabel (eds.): La Península Ibérica entre el Mediterráneo y el Atlántico. Siglos XIII-XV, Sevilla-Cádiz, 2006, p. 738.

${ }^{87}$ Luisa D'Arienzo confirma el patrón comercial de los operadores toscanos y no ofrece noticias sobre el empleo de las galeras mercantiles de Florencia desde la capital lisboeta. Ello explicaría la presencia alterna que Michael Mallett detectó para Lisboa. Probablemente el dato más significativo en este sentido sea la ausencia de fletes hacia y desde Lisboa, tanto en el viaje a Flandes como en el tornaviaje. Cf. D'Arienzo, Luisa: La presenza italiana in Portogallo nell'età di Colombo, Roma, 2003, pp. 549-574.

${ }^{88}$ Cf. HeErs, Jacques: "Le Royaume de Grenade et la politique marchande de Gênes en Occident (XV' siècle)", Le Moyen Age, 63 (1957), pp. 117-118. 
Resulta llamativo que apenas haya noticias concretas sobre la exportación de cueros, virgenes o trabajados, a pesar de que se sabe que los cueros bovinos ibéricos ganaron terreno frente a los berberiscos ${ }^{89}$. Según se ha visto, los fletes de las galeras de Poniente de 1461 preveían la posibilidad de cargar en Cádiz cueros spagnoli de Sevilla, Jerez de la Frontera, Cádiz y Sanlúcar de Barrameda, además de cueros portogallesi, galletiane y berberiscos, presentes asimismo en los fletes de las galeras de Berbería de 1459. Pero la única información en este sentido la proporciona la carta de Angelo Spini desde Sanlúcar de Barrameda a los Medici en 1461, cuando relata las dificultades para cubrir las expectativas comerciales de la línea de Berbería ese año. Así, señala los

danni che levano le chuoia a 8 soldi, che soldi 12 se ne soleva dare, ma al mancho 10 , mai se n'è detto meno le girate a fiorini 2 il chantare, che se ne suole dare fiorini 2 $1 / 2$, e chosì dischorrendo pagoranno a queste ghalee denari 2000 e ghuasteranno questo viaggio di Barberia.

Además, un hombre de confianza del duque de Medina Sidonia les entregaba "libre 12 d'un belissimo brochato d'oro allesandrino e hotto schatole di chonfeti e 2 casse di bischotelli", recibiendo a su vez "un velluto nero per uno giubone; altro non si fe" ${ }^{90}$.

Sin embargo, ni los registros aduaneros pisanos, ni la contabilidad de los Cambini, que importaron ingentes cantidades de cueros portugueses e irlandeses desde Lisboa, arrojan luz sobre la presencia de cueros andaluces o berberiscos embarcados en las galeras mercantiles de Florencia en los puertos del sur peninsular ${ }^{91}$. Por otra parte, cabe recordar que las galeras de Catalonia, cuyos fletes oficiales de 1461 no incluían los cueros, también regresaban a Porto Pisano con chuoia spagnoli $i^{92}$

La carta de Angelo Spini pone de relieve otro problema, que no parece haber sido recurrente: el de la competencia que se podían hacer las líneas. En las rutas de Poniente y Berbería se redujeron o eliminaron las escalas de Provenza y la Corona

${ }^{89}$ Cf. Salicrú i Lluch, Roser: "Los cueros bovinos en el Mediterráneo del siglo XV: retroceso del mercado magrebí y auge de los mercados ibéricos", en CóRDOBA DE LA Llave, Ricardo (coord.): Mil años de trabajo del cuero, Córdoba, 2003, pp. 169-200.

${ }^{90}$ ASF, MAP, X, 211, 18-VI-1461. Ver Apéndice.

${ }^{91} \mathrm{Cf}$. TognetTi, Sergio: "Aspetti del commercio internazionale del cuoio nel XV secolo: il mercato pisano nella documentazione del Banco Cambini di Firenze”, en Gensini, Sergio (ed.): Il cuoio e le pelli in Toscana: produzione e mercato nel tardo Medioevo e nell'età moderna, Pisa, 1999, pp. 17-50. Las aduanas pisanas consultadas por Michael E. Mallet se limitan a recoger la entrada de cueros spagnoli, sin precisar con mayor detalle la procedencia exacta. Cf. Mallett, Michael E.: "Anglo-Florentine Commercial...", p. 265, Appendix II; isdem, "Pisa and Florence in the Fifteenth Century: aspects of the period of the first Florentine domination", en Rubinstein, N. (ed.): Politics and Society in Renaissance Florence, Londres, 1968, pp. 424-427.

92 Así lo demuestran los registros oficiales de las galeras de Siria que pasaron por la Corona de Aragón antes de dirigirse a Porto Pisano en 1465 ( 2 balas de cueros) y 1466 (190 cueros spagnoli); así como los de la propia línea de Catalonia en 1466 ( 3 balas de cuero), 1467 (12 balas de cueros crudos) y 1468 (462 cueros berberiscos). ASF, CM, VII, fols. 61, 64v $\mathrm{v}^{\mathrm{o}}, 68,72,72 \mathrm{v}^{\circ}$. Cf. Asimismo Mallett, Michael E.: The Florentine Galleys..., pp. 127-132. 
de Aragón para no perjudicar a la de Catalonia. No obstante, el puerto de Valencia seguía siendo visitado por las tres, aunque en fechas distintas. Almería, Málaga y Cádiz estaban presentes igualmente en las líneas de Poniente y Berbería, aunque la primera concedía mayor importancia a los puertos malagueño y gaditano, mientras que la segunda se centraba en el almeriense y Sanlúcar de Barrameda. Cronológicamente apenas coincidieron poco más de un lustro, en 1455-61, aunque sólo hay constancia de que las de Berbería pasaran el Estrecho entre 1458 y 1461, lo que posiblemente evitó más conflictos. Efectivamente, ese último año las galeras de Poniente que regresaban del Mar del Norte realizaron una escala no contemplada en Sanlúcar de Barrameda, donde estaban fondeadas las de Berbería. Aunque estas últimas estaban encontrando dificultades en los fletes respecto a los últimos años, según se ha visto, no parece que se debiera a la interferencia con la actividad comercial de las otras galeras en opinión del patrón Angelo Spini (non che loro gli ebino), juicio que no debía compartir el otro patrón, Piero Nasi, que se encontraba "chome disperato, perché si vede to(r)re i noli, ghuastare il viagio e anchora per lo tempo a venire non si troverà chi tolgha più ghalee da Barberia", lo que le llevó a presentar una protesta a los patrones de las otras galeras ${ }^{33}$.

Ya hemos referido el ataque que sufrieron las galeras florentinas en Cádiz en 1441, cuando dos naves corsarias catalanas exigieron que les entregaran las mercancías de genoveses. Tres años más tarde, el 1 de abril de 1444, el genovés Franco Cattaneo formulaba una protesta contra Giuliano Ridolfi y Giovenco della Stufa, patrones de las dos galeras de Poniente presentes en Southampton, a propósito del un flete contratado en Londres por Federigo Centurione, Cristofano Cattaneo y Francesco Nigro, que debían pagar 7 sueldos en moneda esterlina por 300 panni larghi que los florentinos debían llevar a Cádiz o Málaga, lo que se les especificaría más adelante. Sospechando que pudieran no cumplir lo pactado, Franco Cattaneo, en nombre de los genoveses citados, exigía garantías a los dos patrones de que se cumpliría lo contenido en la escritura de fletamiento, algo que Ridolfi y Della Stuffa se apresuraron a asegurar ${ }^{94}$.

Ese mismo mes, el 7 de abril, Forese da Rabatta y sus socios, Gerozzo de' Pilli y Paolo Morelli, florentinos residentes en Southampton, a instancias de los citados patrones Giuliano Ridolfi y Giovenco della Stufa, prometieron pagar a los mercaderes Simone Spinola y Edoardo Cattaneo, genoveses, y Iacopo de Trottis, londinense, 3.300 libras esterlinas si en un tiempo determinado no descargaban en Cádiz o en Málaga -aún por especificar- una cantidad determinada de panni larghi de lana de Hereford y otras mercancías cargadas en las galeras florentinas. Ludovico da Verrazzano, capitán de las galeras de Poniente, suscribió las promesas de sus patrones y prometió dirigirse directamente al puerto gaditano o al malagueño para desembarcar las mercancías citadas ${ }^{95}$.

Estos documentos notariales florentinos pertenecientes a la línea de Poniente inciden en un aspecto llamativo del comercio de las galeras: a pesar de que los fle-

${ }^{93}$ ASF, MAP, X, 211. Ver Apéndice.

${ }^{94}$ Ibidem, s.f., 1-IV-1444.

${ }^{95}$ Una apostilla en el documento señala que el plazo de pago en caso de no cumplir lo acordado finalizaba el 25 de diciembre de ese mismo año. Ibidem, s.f., 7-IV-1444. 
tes de 1461 contemplaban la exportación de paños florentinos a los puertos del sur peninsular, según se ha señalado, lo cierto es que las noticias localizadas se refieren exclusivamente a mercaderes genoveses desembarcando paños ingleses en Cádiz o Málaga. De hecho, aunque tradicionalmente hay acuerdo en que la Península Ibérica era un mercado textil importante, en realidad la actuación de las grandes aziende florentinas se restringía fundamentalmente a mercados muy concretos: los Uguccioni en Valencia y los Cambini en Lisboa. Cabe recordar que la Península estaba más ligada históricamente a los intereses laneros de Europa septentrional a través de las actividades mercantiles de catalanes y genoveses. En consecuencia, la penetración de los paños florentinos habría sido modesta por la competencia, mayor aceptación y demanda de los artículos noreuropeos.

No es casualidad que todas las informaciones se refieran a la década de 1440, precisamente el período en el que las galeras mercantiles de Florencia exportaron entre un tercio y la mitad de todas las exportaciones laneras desde Inglaterra. En consecuencia, tampoco llama la atención la presencia de genoveses precisamente en esas fechas fletando partidas de lana con destino a los puertos atlánticos del sur de la Península Ibérica. Por el contrario, habida cuenta los datos expuestos, sí resulta llamativo que los registros de las aduanas inglesas, que recogen la actividad de los mercaderes italianos en Southampton, no hagan mención, hasta donde sabemos, a las partidas embarcadas por los genoveses sobre las galeras mercantiles de Florencia, lo que contrasta abiertamente con la documentación italiana cuando lo lógico es que proporcionaran informaciones complementarias ${ }^{96}$. Por otra parte, parece claro que los florentinos focalizaron su atención en las variedades más baratas, lo que les diferenciaba nétamente de los genoveses, que además centraban las exportaciones desde Southampton a Málaga y Cádiz en los tejidos laneros de mayor valor ${ }^{97}$.

Ninguna de las noticias recogidas hasta el momento cita la presencia de factores mercantiles florentinos en los puertos de la Bahía de Cádiz. En esta misma línea, no deja de ser llamativo que no tengamos noticias sobre la actuación de los mercaderes florentinos residentes en Sevilla, más aún cuando hemos visto que, al menos en 1461, los notarios de las galeras podían desplazarse a la capital hispalense desde Sanlúcar de Barrameda, donde hacía escala la línea de Berbería. En opinión de Consuelo Varela, no hubo una comunidad relevante en la ciudad antes de 1485, y los mercaderes que figuran operando en ella desde 1421 no permanecían en la ciudad, sino que aparentemente se desplazaban por asuntos puntuales de los patrones. Más aún, los escasos testimonios procedentes de los fondos medíceos ni siquiera confirman el

\footnotetext{
${ }^{96}$ Alwyn Ruddock, que recoge la actividad de los mercaderes genoveses embarcando lana inglesa en Southampton, al analizar el papel de las galeras estatales toscanas, extrañamente, no se hace eco de estos fletes. Para las galeras florentinas en Inglaterra cf. RudDock, Alwyn: Italian Merchants and Shipping in Southampton. 1270-1600, Southampton, 1951, pp. 2, 6, 62-67, 70, 73, 79, 82, 84-85, 96-97, 99-100, 112-115, 120, 132-135, 146-149, 179, 188, 192-193, 198, 206-215, 219.

${ }^{97}$ Cf. Fryde, E. B.: "The English Cloth Industry and the Trade with the Mediterranean", en isdem, Studies in Medieval Trade and Finances, Londres, 1983, XV, pp. 353-358.
} 
empleo de las galeras estatales, sino el de naves genovesas y castellanas, de las que muchas serían vizcaínas, siguiendo los datos proporcionados por Jacques Heers ${ }^{98}$.

En este sentido, resulta significativa la actuación de los Martelli, una de las familias fuertemente ligadas al sistema estatal de galeras mercantiles. Efectivamente, las referencias sobre Sevilla en las Ricordanze de Ugolino di Niccolò Martelli (1433-1483) se centran en las actividades financieras desarrolladas por su hermano Giovanni di Niccolò Martelli, residente en la ciudad en 1439-1440. También hay menciones, escasas, al comercio desarrollado con Piero Doffi empleando la nave de Niccolò Contarini, al envío de un cargamento de lana y 3.387 cueros a Pisa en 1439, más otros 150 cueros por cuenta de los Medici en 1440, con el mismo destino. Pero no hay una sola referencia a la actividad de los convoyes florentinos, si bien sí hay contacto con personas implicadas en su navegación, como fue el caso de Angelo di Guglielmo Spini en 1450, patrón de las galeras de Berbería en 1461 según se ha visto 9 .

Piero Doffi aparece en octubre de 1446 en la documentación del Tribunale della Mercanzia, cuando en su nombre Ludovicho di Niccolò di Ser Ludovicho Doffi expresó que en una carta que le hizo llegar Giovanni di Gherardo se afirmaba que Jacopo Baroncelli entregó a Giovanni d'Astore di Niccolò di Gherardino 1.500 florines de Filippo di Stoldo di Luca di Piero y de Piero di Jacopo di Francescho Neretti "per que'gli trafficare nella ciptà di Sibilia e pel Reame di Spagna e ni qualunche altri luoghi e ni qualunche mecatantie". Sin embargo, en este registro, como en otros examinados del mismo tribunal, encontramos que las autorizaciones para operar en Sevilla y en Castilla nada dicen sobre el empleo de las galeras mercantiles florentinas ${ }^{100}$.

\section{CÁDIZ EN LOS SEGUROS MARÍTIMOS DE LA RUTA DE PONIENTE}

Es ampliamente sabido que los transportes marítimos generalmente quedaban cubiertos con seguros, cuyas tasas variaban ampliamente en función de la presencia

${ }^{98}$ Cf. Varela, Consuelo: Colón y los forentinos, pp. 22-24; 127. Así por ejemplo, en 1451 dos navíos vascos cargaban en Sevilla 1.600 cueros con destino a Porto Pisano, mientras que en 1472 el vizcaíno Juan López de Ondárroa debía llevar de Sevilla a Barcelona, Tortosa y Pisa 442 sacos de lana, 16 balas de grana, 3.300 piezas de cuero y 155 barricas de atún, entre otras mercancías. Cf. HeERs, Jacques: "Le commerce des Basques en Méditerranée au XV siècle", Bulletin Hispanique, 57 (1955), pp. 309 y 316 ;

${ }^{99}$ Cf. di Niccolò Martelli, Ugolino: Ricordanze dal 1433 al 1483, Roma, 1989, pp. 156-157, 159, 160-161, 163, 165, 180, 182, 188-189, 190-191, 197. Hay noticias de la presencia de Piero Doffi en Sevilla de nuevo en 1473 .

${ }^{100}$ En enero de 1446 Jacopo di Piero Baroncelli, en nombre de su hijo Carlo, concertó con Bartolomeo Navelli, ciudadano y mercader barcelonés, que le entregaría 2.000 ducados "per qu'egli traff care nella ciptà di Sibilia, Reame di Spagna e per tucto il detto regno". Por último, en febrero de 1466 Francesco y Bernardo di Nicolò di Francesco Cambini, ciudadanos y mercaderes florentinos, y Giovanni di Bernardo di Guidetto Guidetti, "cittadino forentino dimorante ni Sibilia regno di Portogallo (sic)", entregaban a Piero di Giuliano di Piero Ghinetti, ciudadano florentino, 2.000 florines (1.000 los Cambini y 1.000 Ghidetti) para que mercadeara en Lisboa y el resto de Portugal los cinco años siguientes a partir del 1 de abril de ese año. ASF, Mercanzia, 10831, fol. 9, 24-I-1446; fol. 10v $\mathrm{v}^{\mathrm{o}}, 31-\mathrm{X}-1446$; fol. $62 v^{0}, 3-I I-1466$. 
de factores tan diversos como el tipo de navío, el cargamento, el tonelaje, el armamento, la ruta prevista y sus condiciones, esto es, si sufría actividades piráticas o había conflictos bélicos con acciones de guerra o corsarias. Las características de las galeras, de menor capacidad que otras naves pero con más tripulación y bien armadas, hacían que las tasas aseguradoras de las flotas estatales venecianas o florentinas fueran mucho más bajas que las referentes a transportes sobre otros veleros mercantiles como carracas, balleneros o carabelas ${ }^{101}$. Más aún, algunos mercaderes consideraban tan seguros los convoyes de galeras que ni siquiera aseguraban las mercancías que fletaban en ellos. Un claro ejemplo lo constituyen los Medici, cuyas sociedades en Brujas y Londres tenían expresamente prohibido realizar cualquier tipo de seguro, si bien estaban obligadas a asegurar todos los cargamentos, excepto los que iban sobre las galeras florentinas y venecianas ${ }^{102}$.

Habida cuenta la riqueza y las dimensiones del fondo mediceo, sólo cabe lamentar que no fueran muy activos como aseguradores. Pero hay otras fuentes que suministran datos útiles. Más concretamente dos libros de cuentas, uno del mercader genovés Giovanni Piccamiglio (1456-1459), que abordaremos en primer lugar por cuestiones cronológicas; y otro de la compañía del florentino Bernardo Cambi $(1471-1477)^{103}$.

Giovanni Piccamiglio fue un mercader genovés perteneciente a una familia activa en los registros mercantiles ligures desde principios del siglo Xv. De hecho, el propio Giovanni figura en actas notariales, tanto asegurando transporte marítimo como cargando mercancías en Southampton, Cádiz y Málaga. Para el tema que nos ocupa, los seguros marítimos de las galeras florentinas, se han localizado los siguientes datos: el 3 de septiembre y el 3 de octubre de 1456 asegura mercancía por cuenta del genovés Giorgio Spinola Battista "in galea florentinorum de Janua vel Saona in Cadexe". Con toda probabilidad se trata de la línea de Poniente. Sin embargo, dos años más tarde, el 18 de noviembre de 1458, al registrar un seguro para Federico Centurione "in una ex duabus galeis florentinorum de Saona in Valencia", no hay certeza de que se trate de la misma línea o sea la de Catalonia. No es el caso cuando meses más tarde, el 5 de abril de 1459, Piccamiglio asegura la mercancía de dos genoveses, Federico - de nuevo- y Filippo Centurione, "in duabus galeis florentinorum pro dimidia de Cadixe in Scluxis", pues sólo puede tratarse del viaje hacia Flandes ${ }^{104}$. Se confirma una vez más el papel de los mercaderes genoveses en la actividad de las galeras mercantiles de Florencia, contratando no sólo desde las plazas del sur ibérico como Cádiz o Málaga, sino también desde la propia capital, Génova.

Por su parte, el libro de cuentas de Bernardo Cambi contiene fundamentalmente seguros marítimos de todo tipo. De las ciento trece operaciones registradas, doce

${ }^{101}$ Cf. Tognetti, Sergio: Un 'industria di lusso..., p. 124.

102 Cf. DE Roover, Raymond: Il banco Medici..., pp. 130, 216.

103 Cf. Heers, Jacques: Le Livre de Comptes de Giovanni Piccamiglio, homme d'affair es Génois 1456-1459, París, 1959. El libro de Bernardo Cambi ha sido objeto de una Tesis de licenciatura no publicada bajo la dirección de profesor Henri Bresc, RABINowITz, Assia: Une compagnie mar chande à Florence à la fn du XV siècle: "Il libro di creditori e debitori di Bernardo Cambi", Universidad de París X-Nanterre, 1996-1997.

${ }^{104}$ Cf. HeErs, Jacques: Le Livre de Comptes..., pp. 8, 137, 140, 252, 256, 267. 
(10\% aproximadamente) corresponden a las galeras mercantiles de Florencia. Por su parte, cuarenta y siete operaciones de las ciento trece totales tenían como destino Flandes e Inglaterra, y un poco más de la mitad fueron contratadas en Brujas por su sobrino Giovanni. Lamentablemente, sólo en cuatro ocasiones Cambi asegura las galeras florentinas de esta línea, tres de ellas en 1471 (en los trayectos Sluys-Pisa, Sluys-Southampton y Southampton-Pisa) y una en 1477, en la ruta Pisa-Southampton. Los trayectos asegurados con origen o destino en los puertos de Sevilla, Sanlúcar de Barrameda y Cádiz se refieren a navíos genoveses y castellanos en general ${ }^{105}$.

\section{ALGUNAS CONSIDERACIONES FINALES}

Ante la ausencia de tratados comerciales así como de consulados florentinos en la Corona de Castilla, y dada la reducida dimensión de la colonia localizada en la capital hispalense a lo largo del siglo XV, no se puede hablar de una verdadera penetración comercial toscana en el suroeste de la Península Ibérica. Efectivamente, sólo la presencia de un cónsul de la natio daría a entender una mayor importancia comercial del meridión ibérico, como ocurría en el Norte de Europa (Brujas, Lyon, Londres). Aunque se sabe que la inexistencia de un consulado provocó en otros lugares que los mercaderes más destacados de las naciones toscanas actuaran oficiosamente representando el cargo, la mención del pago en Cádiz de unos diritti di consolato no son concluyentes en modo alguno. En este sentido, cabe recordar que el Estrecho de Gibraltar era una vía de comunicación privilegiada, pero no un espacio económico prioritario para Florencia, cuyas bases transalpinas radicaban en Brujas, Lyon y Londres. En consecuencia, la Señoría florentina no debió sentir la necesidad de establecer consulados en Cádiz ni Sevilla, a diferencia de Venecia y Génova.

En este contexto parece bastante claro que la presencia de las galeras estatales de Florencia en los puertos castellanos a través de las líneas de Poniente y Berbería habría reforzado la presencia de los mercaderes toscanos en el sur peninsular para el período 1425-1478, siendo el modo principal de articular sus actividades comerciales, teniendo en cuenta especialmente las escasas noticias localizadas referentes a la navegación privada. De manera inversamente proporcional, el sistema de navegación de la república habría contribuido en una medida nada desdeñable a la integración castellana en el espacio comercial europeo. Pero, sobre todo, no se puede por menos de concluir que se modifica la visión historiográfica clásica, que en los estudios de conjunto de la actividad comercial exterior de Castilla, además de subrayar la hegemonía genovesa entre las naciones italianas, ha tendido a ligar la presencia y las operaciones de los toscanos en la Baja Andalucía a la expansión atlántica y africana tanto de Portugal como de Castilla, sin olvidar el peso de su contribución a la empresa americana ${ }^{106}$, siempre a partir de finales del siglo xv, minimizando la actuación

${ }^{105}$ Cf. Rabinowitz, Assia: Une compagnie marchande..., passim.

106 Vid. supra nota 4. Cf. además D’ARIEnzo, Luisa: "La presenza italiana in Portogallo e nella Spagna meridionale all'epoca di Cristoforo Colombo", en Due mondi a confronto 1492-1798. Cristoforo Colombo e l'apertura degli spazi, Roma, 1992, pp. 535-565; "I Toscani sulla via delle Indie all'epoca di Cristoforo Colombo", Rivista Geograf ca Italiana, 100 (1993), pp. 321-343; La presenza degli italiani...; Orlandi, Angela: La compagnia dei Botti in Spagna (1520-1560), Tesis Doctoral, Florencia, 1994; 
previa. En consecuencia, determinar el papel de las galeras florentinas es un paso importante para poder alterar de manera significativa el conocimiento y la imagen de los toscanos en la Andalucía cristiana, aunque no sea de forma definitiva. Así, para consolidar el cambio en la percepción de su importancia comercial y mercantil en el Reino de Sevilla sería conveniente examinar con mayor detenimiento los registros conservados en el Archivio Mediceo avanti il Principato que, como puede deducirse a partir de las pocas noticias aportadas aquí, pueden ser más relevantes de lo que en un principio le atribuyó el estudio pionero de Consuelo Varela.

En cualquier caso, dejando de lado las ausencias diplomáticas, consulares y el desarrollo de las colonias, del presente trabajo brota una imagen de los mercaderes florentinos en los mecanismos de importación y exportación comercial de la Baja Andalucía mucho más activa de lo que hasta el momento habían concedido los estudios específicos sobre la materia. Cádiz se confirma como escala de primer orden para la flota florentina -al igual que para la genovesa y la veneciana- con la misma importancia en la documentación oficial que podrían tener las cabeceras de línea de la ruta de Poniente, si bien los escasos registros comerciales localizados se refieren básicamente al servicio prestado a la colonia ligur.

\section{APÉNDICE DOCUMENTAL}

Angelo Spini, patrón de una de las galeras de Berbería, escribe a Cosimo de' Medici relatando la llegada a Cádiz y Sanlúcar de Barrameda de las galeras de su linea y de las de Poniente en el tornaviaje. Se extiende sobr e las dif cultades para comerciar, la competencia real de las galeras de Flandes e Inglaterra y los posibles problemas con corsarios en la ruta de regreso.

$$
\text { A.S.F., M.A.P., X, doc. 211, 18-VII-1461 }{ }^{107} \text {. }
$$

Al nome di Dio. A dì 18 di lulglio 1461.

Spectabilis ac generosus vir et benefatori singhularissimus etc. Non t'ò scritto poi la mia partita perché a Chosimo et a Piero di tutto pienamente ho avisato; credo saranno giunte salve, che chosì piacc(i)a a Dio. E anchora sapevo tu avevi andare al bangnio, però eri stato. Hora m'achade per darti notizia chome la giunta nostra qui nel rio di Sibilia fu a dì IIII ${ }^{\circ}$ di lulglio e che le nostre ghalee di Ponente arivorono in Chadisi sino a dì 2 di lulglio, dipoi a dì 7 se ne venono qui nel rio deto, charcate dereto di 2 ghale(e) sotili del Richase(n)sus ${ }^{108}$ et una nave grossa [...] di 1200 botti e una altra nave di boti 700 e una charovella; e venono insino in sulla bocha del rio e qui si restono, et stetonvi insino a dì 10 . Noi ch'eravamo qui e trovamovi una nave subuagna (sic) di Gienova, di circha botte 1800 et la picciolla di botte 1000 avano fato chonserva chon lloro e lloro chon noi, e alla giunta qui delle navi di Ponente andai a vicitare il chapitano e a llui dissi quello avevo fato. Lui disse voleva anchora lui entrare in deta

\footnotetext{
"Mercanti toscani nell'Andalusia del Cinquecento", Historia. Instituciones. Documentos , 26 (1999), pp. 365-382.

${ }^{107}$ La transcripción completa de esta carta habría sido imposible sin la generosa colaboración de los siguientes colegas y amigos: Francesco Bettarini, Elisabetta Scarton e Ingrid Houssaye-Michienzi.

${ }^{108}$ Galcerán de Requesens.
} 
chonserva, e me domandò quanto pensavo starci. Rispuosili quello prometevono gli ordini, ch'era insino a dì 16 non v'avendo impedimento. Ma il vero è che per sospetto nulla avevo di sichuro et che ne g(i)uravo averve né levato bischotto né aper(...)a e bisongniava dar danari alle giurme delle nostre ghalee, aciò si potesero fornire chome chostume, inteso che ebbe uno de sua padroni che uno scrivano se mandò a Sibilia e ànovi ghuasto questo partito, e a noi chosta questo viaggio. A noi pagorono la metà de' noli, non che loro gli ebino, ma di danni che levano le chuoia a 8 soldi, che soldi 12 se ne soleva dare, ma al mancho 10 , mai se n'è detto meno le girate a fiorini 2 il chantare, che se ne suole dare fiorini $2 \frac{1}{2}$, e chosì dischorrendo pagoranno a queste ghalee denari 2000 e ghuasteranno questo viaggio di Barberia, e per detta chagione sarànne costrati l'uno padrone protestare a' padroni di Ponente e a uno li conficie la chonserva, perché insino a dì 10 di questo salono e lle ghalee e navi d'in sulla bocha del rio, e presono la volta di mare, ed è libero il chamino, ver'è che poi, a dì 13 la sera, tornorono 2 mia huomini mandati per me a sentire novelle da Santa Maria del Porto di Brugha, quivi 25 milglia, e dichono avere inteso da una barcha che tornava da quelo stretto, che à detto che (...).

E' navi sono a Tariffa nello stretto e che anchora vi sono istate vedute 6 altre ghalee più indrieto. Noi qui istimamo per lettere sieno a Sibilia, che dichono il Villamarina è a Chartagenta (sic) sia lui che si sia fato innanzi, che per la fede mia, Giovanni, io credo che non sia chorsale sia rimexo in mare che per noi sia ischontrato, e' nostri nemici chonmincandosi per una à schierati e' provenzali, viniziani, chatalani, bischaini, portochallesi. E hora ultimamente i fiorentini ci son chontro; parmi tropa grande disgrazia che posiamo dire che da' mori abiamo auto insino a quivi milgliore chonpangnia sino che da crestiano, sia di tutto lodato e ringraziato Idio e piac(i)ali di ritorno ristorarci e per tutto mandarci a salvamento.

Il mio padrono, Piero di Lutozo, è ito insino domenicha, a dì 12 di questo, chome disperato, perché si vede to(r)re i noli, ghuastare il viagio e anchora per lo tempo a venire non si troverà chi tolgha più ghalee da Barberia e per chonprare bischotto, polvere da bondarda $\mathrm{e}$ lance e altre chose abisongnano avendo a ritornare in Barberia.

E per non lasciare indrieto una parte, il protesto fec(i)ono a mia padrono a que' di Ponente, mando una copia sotto lettere di Piero tuo fratello.

Il ducha di Medina non n'è venuto anchora da Sibilia e non si crede vengha, perché ieri mandò qui a me uno suo fidato chon lettere di credenza, il quale per sua parte venne a ffare grandissime hoferte di parole, e noi simili a llui e gliene danno per deto fidato libre 12 d'un belissimo brochato d'oro allesandrino e hotto schatole di chonfeti e 2 casse di bischotelli e al suo fidato se donò un velluto nero per uno giubone; altro non si fe'.

Abiamo inteso qui da chi à lettere di chostà che il re Ranieri ${ }^{109}$ passa a Genova con circha 15 ghalee; se così fussi farei dubio di voi in Porto Pisano, però parendovi che chostì scrivo a Piero di farci avisare a Pionbino ho a chavo Chorsicha in qualche luogho che a nostra tornata c'insengneremo tochare in uno di questi 2 luoghi per sentire nuove di chostà e ci sarà charo; puoi rag(i)onare che di qui partireno intorno a dì XXI di questo. Il ragionevole sarebbe, piacendo a Dio, in 2 mesi eser di chostà non di mancho queste cose di ma son sì fallaci che a llui aste, pure il ragionevole sare questo aviso vi sia.

Per grazia di Dio e' ba(n)co vostro de' Medici e tutti gli altri nuostri son sani e stanno bene. Piace a Dio chosì di voi sentiamo che qualuncho di noi chosì desidera.//

Priegoti che alla mangnificenza di Chosimo mi rachomandi e a tutti gli altri tuoi non manchi e salutami il tuo ser Francesco.

${ }^{109}$ Renato de Anjou. 
Non m'achade a dire altro per questa, se non preghare Idio tuti vi ghuardi e in felicissimo stato vi chonservi. Tuo minore e servidore vi si rachomanda.

Agnolo delgli Spini. 